University of Rhode Island

DigitalCommons@URI

Open Access Dissertations

1981

\title{
THE RELATIONSHIP OF SOCIAL PROBLEM SOLIVING TO HIGH SCHOOL PREFORMANCE
}

Barry Alan Plummer

University of Rhode Island

Follow this and additional works at: https://digitalcommons.uri.edu/oa_diss

\section{Recommended Citation}

Plummer, Barry Alan, "THE RELATIONSHIP OF SOCIAL PROBLEM SOLIVING TO HIGH SCHOOL PREFORMANCE" (1981). Open Access Dissertations. Paper 1019.

https://digitalcommons.uri.edu/oa_diss/1019

This Dissertation is brought to you for free and open access by DigitalCommons@URI. It has been accepted for inclusion in Open Access Dissertations by an authorized administrator of DigitalCommons@URI. For more information, please contact digitalcommons-group@uri.edu. 
THE RELATIONSHIP OF SOCIAL PROBLEM SOLVING

TO HIGH SCHOOL PERFORMANCE

BY

BARRY ALAN PLUMMER

A DISSERTATION SUBMITTED IN PARTIAL FULFILLMENT OF THE REQUIREMENTS FOR THE DEGREE OF

DOCTOR OF PHILOSOPHY

IN

PSYCHOLOGY

UNIVERSITY OF RHODE ISLAND 


\section{Abstract}

This research project is undertaken to explore the relationship between social problem solving and the academic and social performance of high school youth. Psychologists have stated that social problem solving is an important component of psychosocial competence. Similarly, both theory and research have linked social problem solving to overt behavioral adjustment to school in populations of young children. In this study, the broader notion that academic and social perfomance in high school will be strongly related to social problem solving was tested.

A total sample of 128 male and female students from grades $9-12$, from selected classes and guidance groups participated in the study. The site was a suburban high school located in southern New England. The students were administered the survey in small groups in one 50 minute sitting. Social problen solving was operationally defined as means-ends thinking (an interpersonal cognitive problem solving measure developed by Platt and Spivack). School performance was operationaliy defined as academic performance (grade point average, number of semesters on honor roll, and post high school training goals) and social performance (a measure of social network developed by Mitchell and extracurricular school activities). Hollingshead's two-factor method was used to measure socioeconomic status. Measures of cormunity social network and cormunity involvement (Mitchell's social network measure, conmunity clubs, and number of jobs) allowed for the comparison of school and community social performance profiles.

The following hypotheses were tested: 1. School performance, 
community performance, and probler solving do not vary by the demographic variables of grade level, sex, or, socioeconomic status. 2. High school students with more effective social problem solving skills will show higher social and academic performance in school.

Results of a series of two-way ANOVA's indicated that the demographic variables of grade level and socioeconomic status differentially affect certain school and community performance indices. Upper class students had more extensively developed school social networks than middle and lower class students. Problem solving abil ity varied by grade level: sophomores, juniors, and seniors had greater social problem solving scores than freshmen. Further, high problem solvers showed more effective academic and social performance in school and better community performance than their counterparts with middle and lower problem solving scores. Multiple regression analyses indicated strong positive relationships between school and community predictor variables and problem solving skills.

The results of this study suggest that social problen solving is significantly related to school and community performance. Notions of problem solving as an active coping strategy for environnental mastery are supported. Schools are postulated to play an active role in the facilitation of problem solving skills and developing the overall social skills of youth. Implications of these results for psychological theory, the practice of school psychology, and the directions for future research are discussed. 


\section{Acknowledgements}

This research project could not have been completed without the invaluable assistance and support of many people. First, I would like to thank Michael Nover, a fellow graduate student, who aided in the collection of data during the pilot testing and has provided encouragement all along the way. I would also like to thank $\mathrm{Clarice}$ Coleman who has patiently typed "rough" drafts, prepared numerous tables, and created order out of my scrambled writing. Appreciation is also extended to my brother Kevin who is also a fellow graduate student and Victor Moniz for their assistance in scoring the problem solving data and putting up with long hours of training.

My doctoral cormittee, Drs. Vosburgh, Kulberg, Lott, and Bumpus, has been a constant source of support not just during the dissertation, but throughout my doctoral program. Each has contributed in his/her own way, balancing constructive criticisn with guidance and encouragement. I would like to extend a special thank you to Bill Vosburgh for $h$ is professional advice and friendship during my five years at URI.

As major professor, Dr. Daniel J. Hurley has set an example for me to strive for both in scholarship and professional excellence. He has demanded thorough research and scholarship in this dissertation, but has been there each step of the way to encourage my progress. I thank $h$ im for his personal and professional support, providing optimism and injecting humor into our discussions whenever possible.

Finally, I would like to thank my family and my future wife, Nancy, for 1 istening to complaints when no one else would hear them and for consistently making me feel that it was all worthwhile. 
ABSTRACT .............................

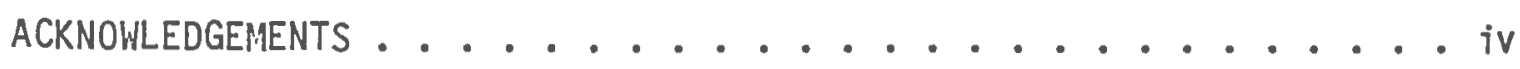

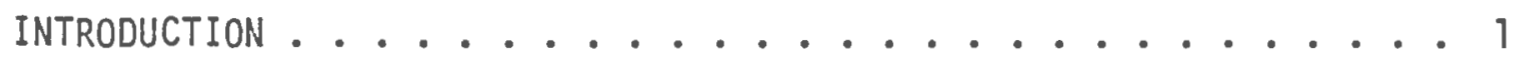

PSYCHOSOCIAL COMPETENCE AND SOCIAL PROBLEM SOLVING ....... 3

Psychoanalytic Theory. . . . . . . . . . . 6

Ego Psychology ................ . . 6

Human istic Psychology. . . . . . . . . . . . . 8

Phenomenological Psychology. . . . . . . . . . . 9

Behavioral Psychology. . . . . . . . . . . . 10

Ecological Psychology. . . . . . . . . . . . . 10

Devel opmental/Soc ial Psychology. . . . . . . . . . 10

THEORIES OF SOCIAL PROBLEM SOLVING ............. 13

Devel opmental/Social ................. 16

Causal Thinking. . . . . . . . . . . . . . 16

Environmenta1 Mastery. . . . . . . . . . . . 17

Behaviorat Anatysis. . . . . . . . . . . . 18

Interpersonal Cognitive Problen Solving. . . . . . . . 19

Intervention Studies ............... 22

Sunmary. . . . . . . . . . . . . . 23

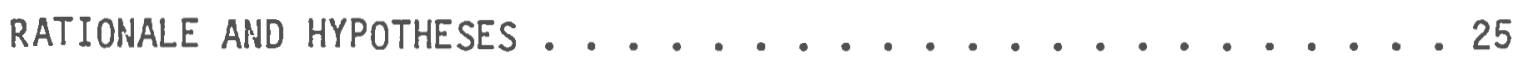

Rationale. . . . . . . . . . . . . 26

Hypotheses and Predictions ............. 29

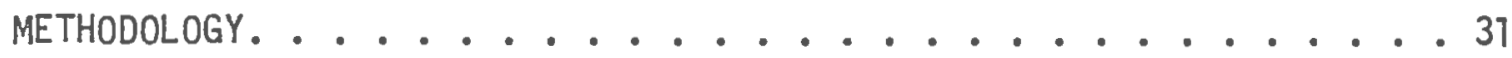

Subjects .................... . . 31

Measures .................... . . . . 33

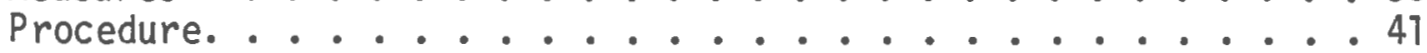

RESULTS. . . . . . . . . . . . . . . . 44

Demographic Results. . . . . . . . . . . . 46

Social Problem Solving Results . . . . . . . . . . . . 62

Intercorrelation of Problem Solving and Performance Variables. . 69

Sunmary. . . . . . . . . . . . . . 77 


\section{TABLE OF CONTENTS}

Page

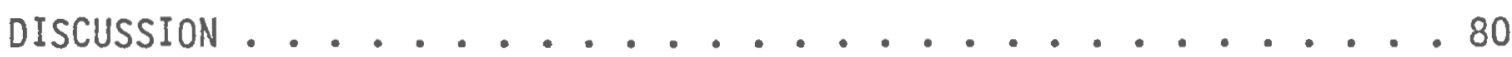

Denographic Differences. . . . . . . . . . . . 81

Social Problem Solving and Environmental Performance . . . . . 82

Development of Social Problem Solving in Adolescence . . . . . 85

Impl ications for Future Research . . . . . . . . . . 89

Implications for Service Del ivery. . . . . . . . . . . 90

Sunnary. . . . . . . . . . . . . . . 91

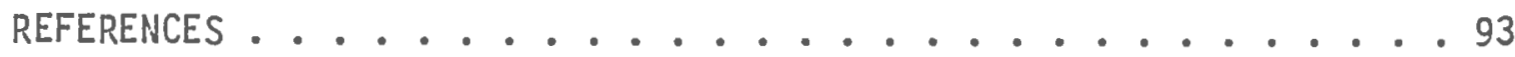

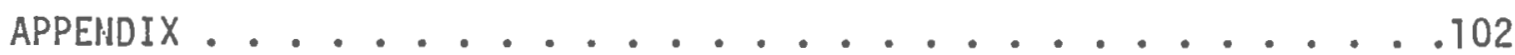

A. Questionnaire ................. 102

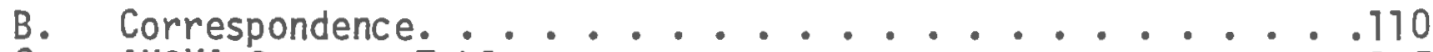

C. ANOVA Sumary Tables. .............. . . . . . 115 


\section{LIST OF TABLES}

Page

1. Psychosocial competence and social problem solving. . . . . 4-5

2. Theories of social problem solving. ............ . . . . 145

3. Summary table of demographic results . . . . . . . . 48-49

4. Mean G.P.A. ratings for sex and grade level groups . . . . . 50

5. Mean number of semesters on the honor roll for sex and grade

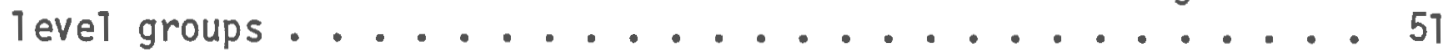

6. Means and standard deviations for performance variables and problem solving groups ............. 58-60

7. Surmary table of problem solving results . . . . . . . 64-65

8. Mean G.P.A. ratings for SES and problem solving groups . . . 66

9. Mean number of semesters on the honor roll for sex and problem solving groups ................ 67

10. Pearson product-moment correlation matrix for social problem solving and school performance variables ......... 71

11. Correlation matrix for Means-Ends Problem Solving. . . . . . 72

12. Relative contributions of each predictor in the problem solving and school performance regression equation ...... 75

13. Relative contributions of each predictor in the problem solving and cormunity performance regression equation. . . . . 76 


\section{LIST OF FIGURES}

Page

1. Social problem solving and high school performance . . . . . 28 


\section{INTRODUCTION}

This research is undertaken to explore the relationships between high school students' performance in academic and social areas and their social problem solving skills. Social problem solving is chosen as the central construct for study because of its 1 ink to psychosocial competence. The many theories that discuss social problem solving as an important component of psychological adjustment also conceptual ize adjustment as an active coping process, whereby the individual must constantly modify his/her problem solving strategy. This "striving" for self improvement and adaptation to the environment needs to be examined in terms of its relevance to developmental processes of high school youth and to specific behavior settings. It is the intent of this study to examine how students perform academically and socially in the adolescent phase of their school career; and relate this performance to their social problem solving skills.

The importance of high school in the socialization of youth and in the preparation for later community ( 1 ife) roles continues to be an important research topic. Youths' perfomance in high school and the ir social problem solving skills, an index of active coping skills, need further detailed examination. This study explores the relationship between students' social problem solving ability and students' social network, involvement in high school activities, and grades. Comparisons are also made to community performance. Performance in high school is chosen for study because its task dernands preview later comunity and job-related task requirements. In this sense, high school experiences are a testing ground for later cormunity 
adjustment. This study first examines the relationship of demographic characteristics to high school performance and social problem solving. Next, the study explores the relationships between various aspects of high school performance with social problem solving skills. Finally, the study looks at the relationship between community performance, high school performance, and social problem solving skills.

This dissertation is divided into the following sections. The first section discusses the importance of social problen solving in theories of psychosocial competence. The second section del ineates specific social problem solving theories. In particular, Spivack and Shure's Interpersonal Cognitive Problem Solving theory is reviewed and utilized as a conceptual model for problem solving in the present study. Empirical studies of social problem solving are also reviewed with in each theory. The third section outlines the rationale for studying social problem solving and high school performance and presents the hypotheses and specific predictions. The fourth and fifth sections present the methodology employed and the results obtained, respectively.

The final part is a discussion of the results and implications for future research and service delivery. The findings are al so discussed in terms of their importance to current theorizing on psychosocial competence. 
PSYCHOSOCIAL COMPETENCE AND SOCIAL PROBLEM SOLVING

Social problem solving as an important component of psychosocial competence has its roots in the post World War II, positive mental health movement. Specifically, Jahoda $(1953 ; 1958)$ was among the first to theoretically relate effective interpersonal problem solving to social and emotional adjustment. Her thinking reflected a more general trend in the social science 1 iterature that identified the proactive or positive aspects of a competent individual. Previous conceptualizations of psychological adjustment have been overly concerned with identifying the absence of mental $i 11$ ness or the individual's compl iance to the norms of society (Smith, 1959; 1968; Tyler, 1978). Social problem solving skills have recently been identified as an important part of an individual's active coping with everyday 1 ife. Other social science theorists have considered active coping as part of the overall personality configuration of an individual. A brief review of major personality theories focusing on psychological competence traces the development of the major tenets of social problem solving thinking. From the different schools of thought a similar pattern emerges: active coping and striving toward mastery are identified as integral components of psychosocial competence (see Table 1). Frequently, social problem solving is mentioned as an essential skill for mastery and active coping to occur. 
Table 1. PSYCHOSOCIAL COMPETENCE

AND SOCIAL PROBLEIY SOLVING

THEORETICAL

PERSPECTIVE

$\operatorname{AUTHOR}(S)$

CRITERIA FOR

PSYCHOSOCIAL

COMPETENCE

Psychoanalytic

Freud (1952)

Ego Psychology

Human ist ic

Phenomenological

G. Kelly (1955; 1958)

$\begin{array}{ll}\text { Behavioral } & \text { D'Zuri17a \& } \\ & \text { Goldfried (1971) } \\ & \text { Anderson \& Messick } \\ & \text { (1974) } \\ & \text { Ojemann (1967) }\end{array}$

Ecological

White (1959)

Hartmann (1951)

Haan (1966)

Loevinger (1966)

Jahoda (1953; 1958)

Rogers (1950)

Al 1port (1955)

Masiow (7955)

Fromm (1947)

J. Kelly (1970;

1979a)
Hell differentiated ego; healthy balance between idego-superego functioning; ego resil iency.

Sense of ego identity; relatively conflict-free ego functioning; notion of positive reality:

intrinsic notivation for "effectance".

Adequacy in love, work, p Tay, and interpersonal relations; efficiency in meeting situational demands; social problem solving process is important.

Self-actual ization; active striving for self-improvement; self as a rational coper; self as an active knower.

Facility in the use of personal constructs; effective hypothes is testing of environmental situations.

Social problem solving is a means of active coping; consideration of alternative solutions and consequences of one's behavior.

Involvement in environment; exploratory behavior is index of coping; use of social problem solving skills; person-environment interaction. 
Table 1 (cont'd) PSYCHOSOCIAL COMPETENCE AND SOCIAL PROBLEM SOLVING

THEORETICAL

$\operatorname{AUTHOR}(S)$

CRITERIA FOR

PERSPECTIVE

PSYCHOSOCIAL

COMPETENCE

Developmental/

Soc ial
Hunt (1968)

Smith (1968)

Tyler (1978)
Environmental experience shapes external motivation to succeed (positive \& negative feedback). Success in environment builds competence motivation...becomes fused with intrinsic motivation to succeed... builds 1) trust in self and others 2) active social problem solving 3 ) sense of self efficacy. 
An important attempt to describe and predict psychosocial competence arises out of psychoanalytic theory. The psychoanalytic perspective posits a healthy, well-differentiated ego capable of rational thought and resiliency under stress as the prime indicator of psychosocial competence (Murphy, 1962; Barron, 1952; Freud, 1952; Loevinger; 1966). Loevinger, (1966) has assembled a variety of ideas about ego functioning into a coherent developmental theory. She suggests that the ego develops from impulse-ridden responding through opportunistic and conformist reactions to integrated autonomy. There should be a healthy balance between $i d$, ego, and super ego functioning in a psychologically healthy person according to psychodynamic theorists. The concepts of ego resiliency, active resistance to stress and integrated responding suggest that the individual has the potential to actively cope with $h$ is/her environment. Ego psychologists have reinterpreted original psychoanalytic theory to place more emphas is on ego functioning and the individual's ability to actively control $\mathrm{h}$ is/her behavior.

Robert White (1959) and Heinz Hartmann (1951) offer two perspectives from ego psychology on the nature of psechosocial competence. These authors address the individual's inner motivation toward competence and rational behavior. This competency motivation arises out of heal thy ego functioning and enables the individual to strive toward relative autonomy from environmental (physical and social) dependence. Independence of environment means relative stability in the face of stress and frustration (Hartmann, 1951). Hartmann (1951; 1964) considers a conflict-free ego capable of resisting stress and producing useful behavior for the individual, 
indicative of psychosocial competence. Further, he suggests that the ego may not always make rational decisions, but the overall utility of the behavior and flexibility of the ego to shift to meet environmental pressures are prime criteria for environmental mastery. Hartmann (1951; 1964) and White $(1959 ; 1963)$ think similarly with respect to the ego's involvement in psychosocial competence. However, the 1atter has continued to focus on intrinsic motivation and explained its composition and functioning in great detail.

White (1959) discusses intrinsic motivation and a process called effectance in his conceptual ization of psychosocial competence. White (1959) suggests that individuals are born with an intrinsic drive toward competence, and that this develops out of healthy ego functioning. A healthy ego may be thought of as well differentiated from id and superego energies and capable of relatively stress-free performance. As an individual receives positive feedback for successful endeavors he/she develops a "set" for responding that White calls effectance. Effectance perpetuates future successes and creates a sense of self worth in the individual. Effectance is directly linked to ego identity in White's theory. He asserts that as the ego develops, it becomes not only sharper and clearer, but also more consistent and free from transient influences. Similarly, it progressively gains autonomy from the daily impact of social judgments and experiences of success and failure (Jahoda, 1958).

Ego psychology's theory on psychosocial competence has enabled psychoanalytic theory to depart from classic Freudian notions of man as an irrational creature by nature, with ego functioning motivated by inner conflicts. White (1959) and Hartmann (1951) have modified 
traditional psychoanalytic notions to suggest that the ego strives toward competence, autonomy, and conflict-free functioning.

Consistent with ego psychology's notions of active coping and motivation toward competence is Jahoda's theory on environmental mastery (Jahoda, 1958). Two themes emerge from the literature within the area of environmental mastery: 1) success; and 2) adaptation. Adaptation, according to Jahoda (1958) has several dimensions including: 1) ability to love; 2) adequacy in love, work, and play; 31 adequacy in interpersonal relations; 4) efficiency in meeting situational requirements; 5) capacity for adaptation and adjustment; and 6) efficiency in social problem solving. Thus, the combination of adaptation to situational demands, social problem solving skills, and success in environmental endeavors seem to be the primary criteria for mastery of environment. This particular conceptual ization represents an attempt to further define psychosocial competence by offering a variety of behavioral demensions. Jahoda's (1958) definition of mastery impl ies that the individual must be aware of situational variables through experience and social learning and that each situation represents a novel set of problems, resources, and solutions. A general trait of psychosocial competency would theoretically enable an individual to adapt more quickly to a novel environment than his/her incompetent peer, but mastery of the environment suggests that experience is the critical variable. Humanistic theorists, Rogers (1950), Allport (1955), Maslow (1955), From (1947) view psychosocial competence as striving toward self-improvement. These theorists assert that individuals actively strive to grow and become psychologically healthy. This process of active 
improvement is exempl if ied in the theory of Allport (1955) where he postulates stages of propriate functioning. Specifically, he states that the "self as a rational coper" is an active problem solving stage. The final stage of self growth he calls "self as a knower". Here the individual evaluates his/her performance and reflects (Allport, 1955). Humanist ic theories represent the view that ind ividuals are actively striving to master their environment to improve themselves.

As a phenomenological theorist, George Kelly (1955; 1958) posits a personal construct theory of personal ity that states that individuals utilize a hypothesis testing model to achieve freedom from environmental manipulation and biological determinism. More specifically, Kelly includes active social problem solving as the bas is for his personal construct theory. He eschews the notions of stimulus and response, motivation, learning, and internal dynamics as explanations of behavior. Instead, he suggests that individuals form hypotheses to aid in the anticipation of other's behavior as well as their own (Monte, 1977; Bischof, 1970). Personal constructs or cognitive representations are formed as a result of hypotheses that prove to be accurate interpretations of reality. Once its effectiveness has been establ ished a construct becomes internal ized and governs future behavior. However, the individuar is not locked into a behavioral pattern dictated by personal constructs. As environmental feedback becomes more discrepant with antic ipated behavior, the individual is free to form alternative constructs that are more accurate predictors of the environment. An impl ic it assumption in Kelly's theory is that effic ient use of alternative constructs is 
indicative of psychosocial competence, whereas, ineffective use of alternative constructs is predictive of incompetence and poor coping strategies. This theory contributes to a theoretical base for later discussions on social problem solving. More specifically, problem solving theory posits an active person-situation interaction that depends upon the individual's abiltiy to generate alternative hypotheses to deal with social problems. The ability to form alternative hypotheses is determined by cognitive skills and social experience.

Behavioral theorists Anderson and Messick (1974), Ojemann (1967), and D'Zurilla and Goldfried (1971) have examined psychosocial competence in terms of adjustment to various environmental settings. In particular, they postulate that social problem solving is an important behavioral skill that enables the individual to actively cope with his/her environment. These theorists assert that social problem solving requires a number of steps including the recognition of a problem, generation of alternative solutions and knowledge of the consequences of one's actions. The behavioral approach to adjustment has further developed the social problem solving 1 ink to adjustment.

James Kelly, another proponent of the positive mental health movement has developed an ecological theory that departs from traditional views of individual functioning. Kelly's major premise is that individuals seek and actively explore situations that will further their mastery of the surrounding environment (Kelly, 1970; 1979a; 1979b). This exploration/mastery notion is similar to current notions of social problem solving.

Developmental psychologists have discussed the emergence of 
psychosocial competence in children. Among then, M. Brewster Smith and J. McV. Hunt have stressed the importance of environmental experience, especially in the first 6-7 years of 1 ife, in molding psychosocial competence notivation. Smith (1968) suggests that children are born with an intrinsic motivation toward competence that becomes fused with an external competence drive formed by experience in the world. He speaks of "vicious" cycles of development occurring when negative feedback from environmental experience is received, and of "benign" cycles of development when positive feedback is received. At an early age, the intrinsic and extrinsic competence drives are fused into one motivation toward psychosocial competence that helps determine future behavior patterns. Smith contends these trends toward psychosocial competence can be influenced by later environmental experience. Conversely, Hunt (1968) argues that psychosocial competence develops almost exclusively out of environmental experience. Successful experiences increase the probability of future successes whereas, negative experiences decrease the chances of success. Both authors agree that a critical component of psychosocial competence is social problem solving. Smith (1968) and Hunt (1968) define social problen solving as the ability to recognize a social problem, generate a number of alternative solutions, and verify the efficacy of the solutions. Both authors assert that this ability is a critical predictor of adjustment to school and other societal institutions.

The development of notions of active coping and environmental mastery have paved the way for specific theories of social problem solving to be delineated. The relationship has been theoretically established between social problem solving and psychosocial competence. 
Namely, social problem solving is an important skill in the overall make up of a competent individual and allows the individual to actively cope with his/her environment.

The next section will review specific theories of social problem solving, discuss the range of intervention studies aimed at training social problem solving skills, and examine the empirical evidence 1 inking social problem solving to overt behavioral adjustment. 
THEORIES OF SOCIAL PROBLEM SOLVING

Problem solving has been widely discussed in the psychological 1 iterature for many years and reviewed periodically (Duncan, 1959; Davis, 1966; Simon \& Nelvel1, 1970). For the most part, psychological research in the area of problem solving has dealt with cognitive styles and abilities when an individual is presented with impersonal tasks such as puzzles, anagrams, and syllogisms. Problem solving has been viewed by the Gestalt theorists (Asher, 1963; \& Sheerer, 1963) as an insightful process that is a basic component of an individual's personality, by information processing theorists (Posner, 1965; Sternberg, 1979) who analyze the types of cognitive skills required to solve different problems, and by intelligence theorists (Merrifield, Guilford, Christensen, and Frick, 1962) who view the skill as an essential intellectual ability indicative of general intelligence. However, the social science literature has begun to develop the role of problem solving as an essential social skill (Spivack \& Shure, 1974; Spivack, Platt, \& Shure, 1976; Kel1y, 1970; 1979a; Mitchell et al., Note 11; Urbain \& Kenda11, 1980; Allen et a1., 1976; Butler \& Meichenbaum, 1980; MCClure et al., 1978; Jaquette, 1980; Jones, 1979). This is particularly evident when one examines the paucity of well controlled experimental studies in the area of social problem solving and adjustment.

There are distinct theories of social problem solving that del ineate the problem solving process (see Table 2). These theories will be summarized in this section of the literature review. 
Table 2. THEORIES OF SOCIAL PROBLEM SOLVING

THEORY

AUTHORS

MAJOR TENETS

$\begin{array}{ll}\text { Developmental/Social } & \text { Hunt (1968) } \\ & \text { Smith (1968) }\end{array}$

Ojemann

(1955; 1967)

Causal Thinking

Jahoda (1958)

1. Ability to generate a1 ternative solutions.

2. Shaped by environmental experience.

3. Important indicator of psychosocial competence.

Problem Solving As

Environmenta1 Mastery
1. Abil ity to recognize social problems.

2. Ability to realize the consequences of one's actions.

3. Causal thinking can be taught to young children.

4. Prime criterion for adjustment to school.
Behavioral Analysis of Social Problem Solving
D'Zurilla \& Goldfried (1971) Urbain \& Kendall (1980)

McClure, Chinsky, Larcen (1978)
1. Means to the end more important than success of solution.

2. Recognition of problem.

3. Choice of most efficacious means is important.

4. Taking action on decision.

5. Important criteria for psychosocial competence.
1. General orienting recognition of problem.

2. Problem definition and formulation; set goals.

3. Generation of alternative solutions/consider potential success of alternatives.

4. Dec is ion making-choose alternative that approximates original goal.

5. Verif jcation/feedback assures outcome.

6. Problem solving as a socia1cognitive process. 
Table 2. (cont'd.) SOCIAL PROBLEM SOLVING

Interpersonal Cognitive Spivack \& Shure Problem Solving (1974)

Platt \& Spivack

(1972a)

Spivack, Platt, \& Shure (1976)
1. Means-Ends thinking = ability to generate and order steps toward a solution.

2. Ability to recognize social problems.

3. Social problem solving can be taught to children.

4. Independent of IQ and mere verbal production.

5. Important indicator of adjustment.

6. Awareness of consequences 
Developmental/social. Developmental psychologists have addressed the relative import of social problem solving skills as an indicator of psychosocial competence or adjustment. Among them, J. McVicker Hunt (1968) conceptualizes problem solving as a critical coping strategy that can predict future adjustment to a variety of societal institutions. He describes social problen solving as the ability to recognize a problem and formulate viable alternative solutions. Further, he states that the relatively "plastic" child can be exposed to a variety of experiences that will increase problem solving abilities and increase his/her control over his/her behavior. Similarly, M. Brewster Smith (1968) describes social problem solving as an active solution-generation process by which individuals cope with typical social problems.

Others have considered social problem solving as cause-effect thinking (0jemann, 1955, 1967), as a cognitive-behavioral process (Jahoda, 1953, 1958), as a behavioral hierarchy (D'Zurilla \& Goldfried, 1971), and as an interpersonal cognitive process (Spivack \& Shure, 1974; Spivack, P1att, \& Shure, 1976). These theories represent the base from which host psychologists analyze social problem solving. They will be reviewed briefiy.

Causal thinking. Ojenann $(1955 ; 1967)$ examined the relationship between causal thinking in social problems to classroom adjustment in young children. He was able to train young children to recognize the underlying dynamics of a variety of classroom problem situations and demonstrate a significant improvement in classroom adjustment as a result. ojemann asserts that social problem solving is a teachable skill that allows children to understand the meaning behind surface behavior and apply the techniques to everyday situations. Through his 
research, Ojemann et al., (1955) was able to empirically verify the relationship between social problem solving and overt classroom adjustment in young children. Limitations in $h$ is efforts included use of a 1 imited number of problems, short-term training, teacher ratings of behavioral adjustment, and a 1 imited age range of subjects.

Environmental mastery. As previously alluded to, Marie Jahoda (1953; 1958) has stressed the importance of social problem solving as a critical indicator of psychosocial competence. Jahoda's conceptual framework is central to the present research in that Spivack and Shure (1974; 1976) have integrated her model into their theory and research. Jahoda (1953) discusses two perspectives on social problem solving. She speaks of problem solving as an ability to reach an end product successfully. But, success in social problem solving is often dependent upon circumstances beyond the individual's control. Hence, this circumstantial determinant renders social problem solving as a somewhat ambiguous attribute of mental health. Jahoda asserts that conscious awareness, long-term or short-term, of a social problem, understanding the means to reach a solution, and the intention to act on the problem are more important attributes of problem solving than the success of the solution or the number of solutions generated. Jahoda (1953) provides further insight into the process of social problem solving by distinguishing between three dimensions: 1) awareness of a social problem; 2) consideration of the relevant means toward a solution; and 3) choice of the most efficacious means. This conceptualization of the problem solving process seems to parallel several formal descriptions of the thinking process where the individual must recognize the impending problem, think of steps to 
solve the problem, and choose the best route to the solution (Duncker, 1945). An important consideration in Jahoda's problem solving theory is delay of gratification le.g., the ability to consider all the steps in the problem solving process before acting). Jahoda states that the maximum degree of problem solving effectiveness occurs when an individual combines: 1$)$ the tendency to complete all the stages of the problem solving process; 2) maintenance of an appropriate feel ing tone that will facilitate the process; and 3) direct attack on the problem. Jahoda has suggested that research should verify whether people who are mentally healthy are more 1 ikely to be successful as problen solvers.

Behavioral analysis. D'Zurilla \& Goldfried (1971) offer a related theory on problem solving. They begin by defining a problem:

The term problem will refer here to a specific situation or set of situations to which a person must respond in order to function effectively in his environment. To point out this situational emphas is (as opposed to the traditional "intrapsychic" connotation of the word "problem" in cl inical psychology), the term problematic situation will be used in most instances in place of "problem". In the present context, a situation is considered problemat ic if no effective response alternative is inmediately available to the individual confronted with the situation. (pp. 107-108).

D'Zurilla \& Goldfried (1971) emphasize the internal cognitive processes that are important to problem solving, processes similar to "the operation of cognitive strategies or learning sets... which enable an individual to create or discover symbolically solutions to a variety of unfamiliar problems" (p. 108). These authors have developed a five stage hierarchical theory that describes the social problem solving process. 
The stages include:

1. General orientation. This stage involves recognition of the problem and the realization that actively pursuing a solution is the best way to resolve it.

2. Problem definition and formulation. Here, the specific aspects of the problen are "stated" and goals for problem resolution are set.

3. Generation of alternatives. This step involves the formulation of possible solutions in order of their probable successes. The consideration of many alternatives is stressed.

4. Decision making. Here the consequences of each prospective solution must be weighed and the alternative that comes closest to the original goals should be implemented.

5. Verification. This final step involves the assessment of the actual outcome in light of original predictions. This serves as a feedback mechanism for future problem solving attempts.

D'Zurilla \& Goldfried (1971) have specifically defined interpersonal problem solving as a behavioral process which creates a number of viable response alternatives and increases the 1 ikel ihood of selecting the most effective response for dealing with the social problem. This approach to the social problen solving process is similar to the theory offered by Spivack and Shure (1974). Both theories draw heavily on the original model of problem solving described by Jahoda $(1953,1958)$. The important advantage to the theory of Spivack and his co-workers is the emphasis on an interpersonal problem solving skill called means-end thinking. Spivack and Shure's (1974) theory on interpersonal cognitive problem solving will be described next and the relevance of means-ends thinking will be presented and verified empirically.

Interpersonal Cognitive Problem Solving. Little evidence exists to 
suggest that solving a pencil and paper maze or puzzle will predict how well an individual will handle an interpersonal conflict. In their empirical investigation into the relationship between social problen solving and adjustment, Spivack and Shure state that the domains of impersonal and social problem solving are disparate and require distinct and separate theoretical analyses (Spivack \& Shure, 1974; Spivack, P1att, \& Shure, 1976; P1att \& Spivack, 1972; P1att, Spivack, Altman, Altman, \& Peizer, 1974). Spivack, Shure, and their co-workers have identified a number of interpersonal cognitive problem solving skills that underlie the problem solving process. Among these abilities, the following have been identified as the most important indicators of overt social adjustment in children when the effect of intelligence is controlled.

1. Alternative thinking is defined as the ability to generate many possible alternative solutions to a specific interpersonal problem situation.

2. Consequential thinking is described as the ability to conceptualize the potential consequences of a particular alternative and to base the problem solving decision on this information.

3. Means-ends thinking is defined as the ability to plan the steps (means) necessary for a particul ar goal to be reached, to recognize the potential obstacles impeding the problem solving process, and to utilize an appropriate time framework as a guidel ine toward meeting the goal (e.g., knowing when to wa it before initiating action).

The latter ability has been identified as the most important of the three. The means or ends thinking process is similar to the concept that Jahoda (1953) defined as a more important skill than generating al ternatives and reaching a solution.

As the primary exponents of an interpersonal-cognitive problen solving approach to children's adjustment, Spivack and Shure and their 
collaborators have conducted extens ive research in this area. From their data, they conclude that: 1) some children are significantly more capable than others to think through and solve typical interpersonal problens; 2) effective social problem solvers display significantly better adjusted behavior in school as compared with their more deficient problem solving peers; 3 ) exposure to interpersonal cognitive problem solving training significantly increases children's abil ity to solve social problems with peers and adults; and 4) the effects of training these skills occur with in a wide intelligence range $(70-120+)$ and seem to have relatively enduring results. Spivack and Shure contend that social problem solving is relatively independent of general intelligence and mere verbal production, as well as socioeconomic status (Hopper \& Kirschenbaum, Note 1). These authors contend that individuals who can think through and solve social problems, judge the valence of potential outcomes, and appreciate the underlying causal dynamics of an interpersonal solution will: 1) be less likely to make impulsive mistakes; and 2) suffer less frustration from failure actions leading to a decrease in maladaptive functioning. Further, Spivack and Shure (1974) have found the interpersonal cognitive problem solving process of means-ends thinking to discriminate between aberrant populations and "normal" populations across many groups (e.g., del inquents, psychiatric patients, drug addicts). Means-ends thinking has also been positively related to development of social networks in groups of adult psychiatric outpatients (Mitche11, Note 11). Patients with better social problem solving abilities (means-ends thinking) tended to have more effectively developed support networks and manifested better overall social adjustment to their environment 
(Mitche11, Note 11).

Intervention studies. There have been a number of intervention studies aimed at improving problem solving skills where overt behavioral/social adjustment was al so measured (e.g., Urbain \& Kendall, 1980; McClure, et a1., 1978; Sarason \& Ganzer, 1973; Spivack \& Shure, 1974; Spivack, Platt, and Shure, 1976; Shure, 1979). For the most part, problem solving training has been shown to increase overt adjustment to a particular environment. Most of the intervention studies involve young children trained in school, behavioral where adjustment to school is measured by behavioral observations, teacher ratings, and/or sociometric ratings. Problen solving training studies have occured in other environments including clinics, hospitals, and at home (family) (Urbain \& Kenda11, 1980). The results of a number of studies suggest that social problem solving training improves adjustment at home and in schoot (Shure \& Spivack, 1978; Al exander \& Parsons, 1973; Parsons \& Alexander, 1973; Robin et a1., 1977). When problem solving has been theoretically and empirically linked to adjustment in a particular environment the scope of the measured adjustment has been restricted. That is, adjustment has been considered as overt behavioral adaptation. More complete measures of functioning in an environrnent, especially schools, have been missing from the 1 iterature.

The social science 1 iterature suggests that social problem solving should be considered as a domain separate and distinct from the abstract or impersonal problem solving area (Spivack \& Shure; 1974). Spivack and Shure have offered the most well-developed and extensively researched theory and system to analyze the social/interpersonal 
problem solving domain. They have examined how young children adjust to school and have analyzed the effects of their intervention program on the adjustment of young children to school. The success of their program with young children has been demonstrated. However, there are a few areas where additional research would complenent our knowledge of interpersonal cognitive problem solving. First, Spivack and Shure focus largely on young children and their overt behavioral adjustment to school. They have examined interpersonal problem solving from a mental health perspective, choosing not to look at academic and social performance with respect to the total school environment. Second, Spivack and Shure have not examined adolescents' performance in their school environment. Rather, they have chosen to assess the adjustment and relative social problem solving skills of special populations of adolescents (e.g., hero in addicts, delinquents, psychiatric patients). Third, Spivack and Shure have found no sex differences on their measures of interpersonal cognitive problem solving. This finding merits further exploration in light of the many sex differences found along other personality dimensions (Hoffman, 1977; Stein \& Bailey, 1973; Maccoby \& Jackl in, 1974).

Summary. Each of the authors discussed in this section consider social problen solving as a critical component of an individual's active coping ability. In addition, a particular problem solving process (means-ends thinking) has been proposed and studied as more important than the ability to consider consequences and the generation of many alternatives. Spivack \& Shure have considered this spec if ic problem solving process in their intervention programs for children. Their research and others have 1 inked means-ends thinking to overt 
behavioral adjustment to school and home environments. However, certain areas of the relationship between social problen solving and environmental performance have not been explored. Since the 1 ink between problem solving and performance has been established, it is necessary to consider broader notions of environmental performance and different developmental groups in order to further examine the relationship. Performance in any environment requires more than just overt behavioral adjustment. As a sole index of environmental performance, even in school, overt behavioral adjustment is not comprehensive enough to provide a full explanation of what dimensions of the environment a person is adjusting to effectively (e.g., social; participation; task demands). Social problem solving has been studied in aberrant populations of children, adolescents, and adults. Although problem solving training programs have been implemented on "normal" populations with positive results, the age range that has been studied has included only children. Normal adolescent populations have not been studied. In this research project the focus is on addressing these empirical and theoretical gaps in the social problem solving literature. 


\section{RATIONALE AND HYPOTHESES}

This research project is designed to examine the relationship between social problem solving and adolescents' high school performance. Social problem solving has been traced to notions of active coping and environmental mastery. It is considered by many psychologists to be a critical component in the cognitive-behavioral repetoire of a competent person. Specific theories of social problem solving were reviewed and the process of problem solving as opposed to the generation of many alternatives was highl ighted as the most important consideration. Thus, a theoretical link between the social problem solving process and the psychosocial competence constructs of active coping and environmental mastery has been establ ished. Also, the domains of social and abstract (impersonal) problem solving have been discussed and examined as separate processes. Although both processes require a significant cognitive component, abstract problem solving is more strongly related to traditional notions of intelligence whereas, social problem solving is somewhat independent of verbal intelligence.

Empirical investigations into the relationship between social problem solving and environmental performance have shown that the two are significantly positively related. Intervention studies that train social problem solving skills have demonstrated that more effective social problem solvers are better adjusted to school and home environments. Problem solving has been positively related to the development of social support networks in the community (involving mostly family members). A particular conceptual ization of problem 
solving, means-ends thinking, has shown the strongest relationsh ip to overt behavioral adjustment to the school environment. Means-ends thinking has been shown to discriminate between aberrant and normal populations across a wide age range. Also, this interpersonal cognitive problem solving skill called means-ends thinking has not been shown to vary significantly by the demographic variables of race, sex, and socioeconomic status.

\section{Rationale}

The relationship between social problem solving and environmental performance has been explored from a 1 inited age and developmental perspective and with restricted notions of what constitutes environmental performance. More spec if ically, the development of social problem solving in normal high school adolescent populations has been ignored. When social problen solving has been related to school performance only the overt behavioral adjustment of the individual was measured. Overt behavioral adjustment is not an adequate conceptualization of school performance. Without careful examination of the tasks required by public schools, one cannot fully explore the relationship between problem solving and school performance. Since the majority of children in the mainstream of schools manifest adequate behavioral adjustment, a closer inspection of school performance is necessary.

A more comprehensive definition of school performance includes the major task denands in the academic and social areas. In particular, the high school environment allows a student to participate in activities (e.g., sports; clubs), relate with peers and adults, and 
achieve grades for classroom learning. Social problem solving has not been related to a complete index of high school performance in the 1 iterature to date. This study will examine adolescents' social problem solving processes (means-ends thinking) and school performance in academic and social areas. A study of relatively normal adolescents will contribute to the examination of the role social problem solving plays in environmental performance (see Figure 1 ).

Previous studies of the social problem solving process have shown 1 imited differentiation by demographic groups. The present study will attempt to confirm these findings in a normal adolescent population. 
Figure 1. Social problem solving and high school performance

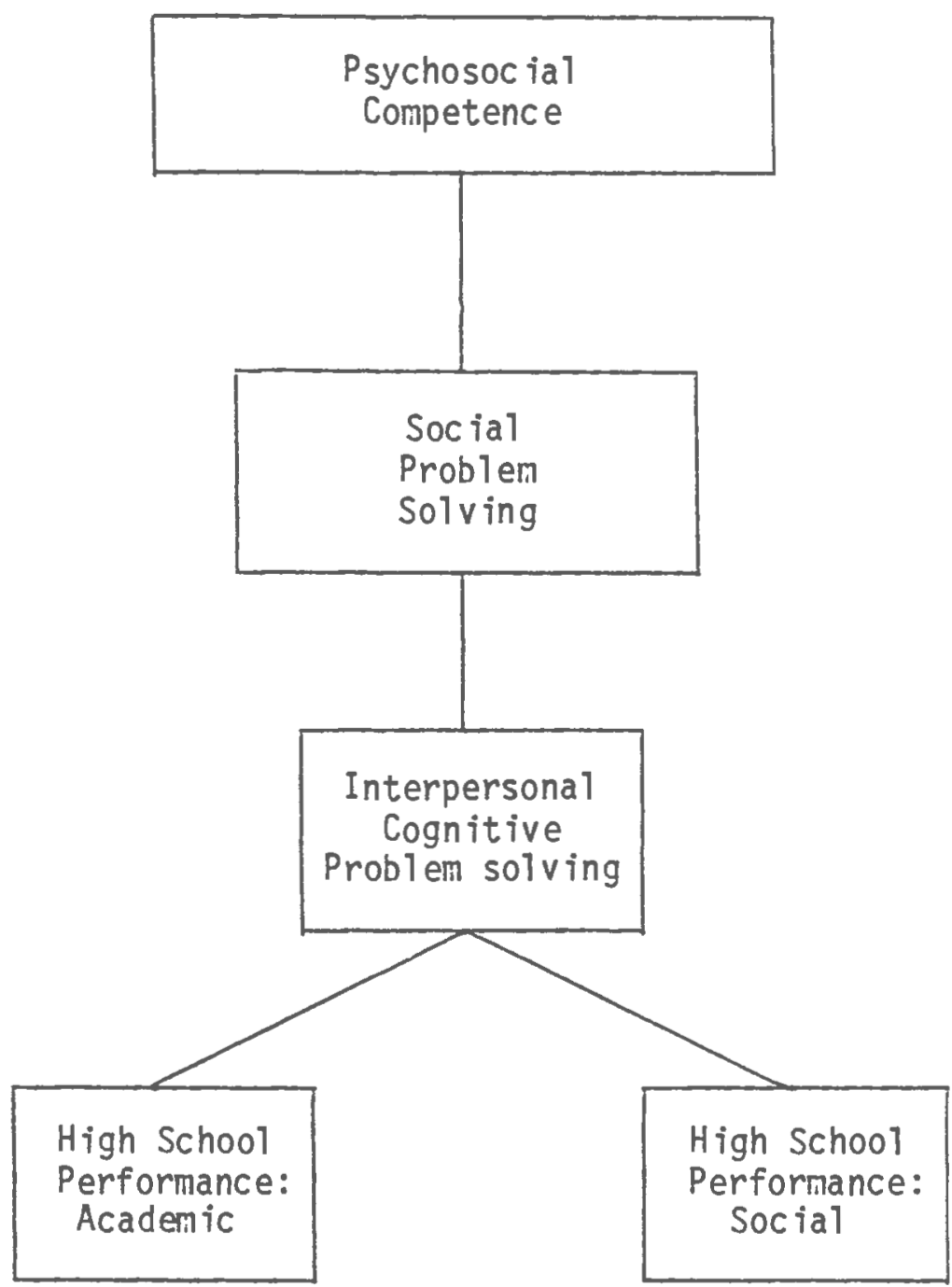




\section{Hypotheses and Predictions}

The first question addressed by this project is whether or not discernable patterns exist in the social problen solving abilities and school performance of students in the high school environment. Thus, the first hypothes is is stated:

First hypothesis. It is hypothesized that social problem solving skills, academic perfomance, and social performance do not vary by sex, grade 1 eve1, or SES.

This hypothes is leads to the following predictions about social problem solving and high school performance:

1. It is predicted that there will be no differences by grade level in: (a) the social problem solving skills of high school students; (b) the academic performance of high school students; (c) the social performance of high school students.

2. It is predicted that there will be no differences by sex in: (a) the social problen solving skills of high school students; (b) the academic performance of high school students; (c) the social performance of high school students.

3. It is predicted that there will be no difference in SES in: (a) the social problem solving skills of high school students; (b) the academic performance of high school students; (c) the social performance of high school students.

4. It is predicted that there will be no interaction effects in: (a) grade level by sex; (b) grade level by SES; (c) SES by sex.

The second question addressed by the research project is the relationship between high school perfornance (academic and social) and social problem solving. Thus, the second hypothes is is stated: will exhibit higher academic and social perfomance. 
This hypothes is leads to the following predictions:

The more effective the social problen solving skills the:

(a) higher the academic performance; and (b) greater the social performance.

From these hypotheses, the following variables are operationally defined for use in this study. The demographic or student attribute variables of sex, grade level and SES are included in order to reflect the potentially different socialization experiences attributable to different group membership. Grade level and sex are reported by the student. The socioeconomic status of the student is operational ized by the education level and occupation the student reports for each parent.

Social problem solving, the first major construct of this study, is defined as interpersonal cognitive problem solving (means-ends thinking). Here, students respond to ten problem stories and this score is used as the operational definition of social problem soiving. High school performance is the second major construct of this study.

It is divided into: 1. academic performance, operationally defined as students' self-report of grades; teachers' ratings of students' academic performance; and number of semesters on the honor roll the previous year; and 2. social performance, operationally defined as students' report of their social support network (size, diversity, and reciprocity) in school; participation in school clubs and activities; and post high school training goals. 
METHODOLOGY

\section{Subjects}

One hundred-thirty seven $(N=137)$ students were surveyed from grades 9 through 12 at a medium-sized high school located in southern New England. In order to include equal numbers of male and female students and equivalent groups at each grade level, 16 male and 16 female students' questionnaires were randomly selected from each grade level. Thus, a final sample of 128 students was created for inclusion in the present study. More specifically, there were 32 students $125 \%$ of the sample) at each grade level and a total of 64 male (50\% of the sample) and 64 female students (50\% of the sample). The socioeconomic measure utilized in the present study (described later in this section) y ielded the following breakdown by group: there were 44 students (34\%) in the upper group, $26(21 \%)$ in the middle group, and $58(45 \%)$ in the lower group.

The suburban town in which the high school in this present study is located has a population of approximately 35,000 and a relatively large working and professional class distribution (1980 census). There are relatively equal numbers of working class and professional class famil ies.

A11 procedures for subject sampling and partic ipation were negotiated with the superintendent of school's office and with the principal of the high school. An attempt was made to acquire IQ data for the sampled students from their school records. These negotiations were unsuccessfui because IQ data were not available for all students 
and because of potential violations of student confidentiality. The 9th and 10th grade students were from randomly selected guidance groups. These guidance groups were required of all students during the ir freshman and sophomore years in high school as part of a standard affective education curriculum; therefore, there were no significant pre-selection criteria that might bias the study. Guidance groups were selected from a master list of counselors and their respective groups that was given to the experimenter by the high school principal. Students were randomly assigned to guidance groups previous to the start of the school year by the Director of Guidance. The experimenter picked groups randomly from the master 1 ist and attempted to include an equivalent number of groups for each counselor. In total, nine guidance groups were sampled from four counselors.

By arrangement with the high school principal, the 11 th and 12th grade students were selected by classes from the social studies department. Two teachers were designated by the principal and the experimenter sought their voluntary cooperation. After the teachers volunteered the ir classes and cooperation, five class groups were chosen by the experimenter. The selection process was not random, but was done to include groups of varying levels of abilities as noted by the teachers. Social studies courses are offered to all 11th and 12th grade students and they are expected to take one before graduation. A7 though students from business, vocational, and precollege tracts were represented, the majority of students were in the latter category. This sample is representative of the high school population in the present study and there is no reason to bel ieve that any pre-selection criteria biased the sample. 


\section{Measures}

This discussion will focus on how the following variables included in this research project will be measured. The various measures selected for this survey instrument are the standard measures that have been used in studies of social problem solving skills, social competence, and social network. As the measures to be util ized by each variable are presented, the studies from which they were taken will be cited and any adaptations made for this study will be described. Rel iabil ity and val idity data are offered.

Performance in high school. As previously discussed, this variable is divided into the components of academic and social performance in school.

1. Academic performance. Students were asked to pick the grade, $A+, A, A-, B+, B, B-, C+, C, C-, D+, D, D-$, or Fail that best describes the ir overall work in school. Each rating, student and teacher/counse1or, was converted to a score from 1-13 depending on the grade circled (e.g., $A+=1, A=2, A-=3, \ldots$ Fai1 $=13$ ). The student and teacher/counselor ratings were compared using a Pearson product-moment correlation procedure. A coefficient of $\underline{r}=.92 \underline{p}<.001$ was obtained between these two ratings.

The teacher/counselor rating was selected as the index of grade point average for subsequent data analys is for the following reasons: (1) its high correlation with the student rating; (2) a simpler more parsimonious data analysis procedure; (3) its referent to teacher's/ counselor's familiarity with students' actual performance; and (4) the inclusion of only the past two years academic performance, whereas students were asked to rate the ir overall grades. 
Students were also asked to report the number of marking periods they were on the honor roll last year (all students had an honor roll last year). Finally, students were asked if they planned to enter some post high school training program (e.g., college, vocational program, beautician's school). They answer yes, no, or undecided.

2. Social performance. A measure of social network reported by Mitchel1 (Note 10, 11); Hirsch (Note 12); and Sandler and Barrera (Note 15) was used as an index of social performance in school. This measure required students to identify by initials, the four persons whon they felt were closest or most important to them in school. Then, students indicated their relationship to each support person 1 isted (e.g., friend, teacher, counselor) and whether they relied on that person for material assistance, emotional support, and/or companionship and recreation. Finally, the student was asked whether each support person 1 isted relied on the student for material assistance, emotional support, and/or companionship/ recreation. Students checked "yes" or "no" for the support categories across each support person 1 isted. Each "yes" answer received a score of 1, and "no" answers were scored 0. The social network measure yielded the following five separate scores: (1) Number of support people 1 isted (score 0-4); (2) Multidimensionality (score $0-4$ ), comprised of the number of relationships 1 isted that offered more than one category of support (e.g., material assistance and emotional support); (3) Rel iance on others (score 0-12) comprised of the number of "yes" answers checked for support received from others; (4) Instrumental ity (score $0-12$ ), comprised of the number of "yes" answers checked for support given (others' rel iance on the 
student); and (5) Total network score $(0-24)$, which consisted of the total number of "yes" answers checked across all support categories for a11 support persons 1 isted. Students' social networks were al so scored for reciprocity and type of relationships. An index of reciprocity was calculated for each support relationship listed by assigning a one (1) to each relationship that had an equal number of "yes" answers for support received versus support given and a two (2) for relationships that had an unequal amount of support given versus received. Thus, relationships fell into the categories reciprocal or nonreciprocal. The reciprocity score was a measure of the balance between material assistance, emotional support, and companionship/recreation that was given to support people and received from them. Relationships vere also categorized according to peer or adult affiliation for further analysis.

The multidimensional ity and instrumental ity of support networks has been found to distinguish: (1) the degree of psychological effectiveness between "cl inical" and "normal" populations (Tolsdorf, 1976; Mitche11, Note 10,11$)$; and (2) the abil ity to solve problems connected with life transitions (Hirsch, Note 12). Further, Mitchell (Note 11) has found: (1) a significant positive relationship ( $\underline{r}=.62$ $\mathrm{p}<.01$ ) between the number of intimates subjects reported and the number of close friends that family members reported clients as actually having; (2) a significant positive relationship between social network size and interpersonal cognitive problem solving $(\underline{r}=.31, \underline{p}<.05)$; and (3) a significant relationship between independence (autonomy) and support from peers $(\underline{r}=.43, \underline{p}<.01)$. Although the relationsh ip between network size and interpersonal cognitive problem solving was 
statistically significant it was not practically significant because it only accounted for $9 \%$ of the variance.

A pilot study by the present author and associates established further reliability information on the school social network measure. This study, conducted in an urban high school found that the social network index was stable over time. Students from grades 9-12 were administered the social network twice with a three week interval. The test-retest rel iab il ity coeff ic ient for instrumental ity was $\underline{r}=.69$, $\mathrm{p}<.001$ and for multidimens ional ity $\underline{r}=.70, \mathrm{p} \angle .001(N=108)$. The tests-retest interval for the social network measure was three weeks.

Social performance in school was al so measured using number of school clubs. Students were asked to 1 ist the clubs or organizations they belonged to now (inside and outside of school...for example, student government, sports teams, etc.). School clubs and activities were coded if they were associated with the high school. Thus, school social performance consisted of number of school clubs and the social network indices.

Performance in the community. This factor was included to provide an index of comparison for school performance. Specifically, commun ity performance included: number of jobs; type of present job; type of past job; number of community clubs; and community social network.

1. Jobs. Students were asked to 1 ist summer and part-time/yearround jobs they have held this year and in the past. The variable, "number of jobs", was comprised of the total number of jobs listed in al1 categories. The variables "present jobs" and "past jobs" were divided into the categories: no job; summer job only; part-time/year-round only; and both surmer and part-time/year-round 
according to what the student 1 isted.

2. Clubs. The variable "community clubs" was comprised of the total number of community clubs the student 1 isted as being involved with currently (see club variable under school performance section above). Specifically, community clubs were coded as such when they were not associated with the high school.

3. Community social network. This measure was similar to the social network measure previously described for the school. The only administrative difference was the directions used: students were asked to 1 ist the initials of the four persons to whom they felt closest or most important to them outside of the ir family members. These four persons could include school relationships. Students also indicated their relationships with each support person 1 isted. Thus, the indices of number of support people, multidimensionality, instrumentality, rel iance on others, and total network score were measured and scored in the exact manner they were for the school network. A1so, community relationships were scored for reciprocity and type in the same manner as school relationships. The number of 1 isted support people on school and community networks allowed for the creation of an additional variable, total support people. This was calculated by summing the number of different relationships included on the school and cormunity networks (score $0-8$ ). The total number of support people offers a measure of total social network size.

Social problem solving. The construct of social problem solving was measured with the Means-Ends Problem Solving test (MEPS) developed by Platt and Spivack (Note 13) as an index of interpersonal problem solving ability. The MEPS test has been found to discriminate between 
psychiatric and normal populations along the dimension of psychological adjustment across many age groups (Spivack \& Shure, 1974; Spivack, Platt, \& Shure, 1976). A similar procedure has been shown to predict behavioral adjustment to school in populations of younger children (Shure, 1979).

The present study utilized the entire standarized MEPS procedure that presented students with ten short stories, each with a beginning and an ending section. The student was asked to write the middle of the story. Specifically, they were asked to write a few sentences that would connect the beginning of the story (problem description) to the end of the story. There were both male and female versions to all ten stories, differing onty by the gender of the names and pronouns used. Consequently, female students received stories with the female gender and male students received the stories with the male gender.

The MEPS instrument has extended rel iability and validity data (Spivack \& Shure, 1974; Spivack, P1att, \& Shure, 1976; P1att \& Spivack, 1974a; 1974b; 1974c; 1977; Note 13; Note 6). The authors report: discrininant validity with college students and del inquent adolescents; (2) content validity through a series of three factor analytic studies that identify one general problem solving factor suggesting that all the stories measure the same quality of thinking; (3) construct val idity using college students and other measures of problem solving; and (4) predictive validity with a population of youthful heroin offenders (P1att \& Spivack, 1975). In addition, the factor analytic studies of the MEPS test $y$ ielded the general problem solving factor just mentioned and three spec if ic factors: Factor I, problem production and solution; Factor II, interpersonal facilitation; and 
Factor III, consideration of consequences. These three factors accounted for $70 \%$ of the total variance (Platt \& Spivack, Note 13).

Rel jabil ity data on the MEPS tests were obtained through a series of five studies using mostly psychiatric populations (Platt \& Spivack, 1975). Test-retest rel iabil ity coefficients were $\underline{r}=.59, p<.05$ (test-retest time interval $-2 \frac{1}{2}$ weeks) $r \underline{r}=.43, \mathrm{p}<.001$ (test-retest time interval -8 months); $\underline{r}=.64, p<.05$ (test-retest time interval - , 5 weeks) for del inquent fernale and male adolescents and male college students, respectively. Coefficients of internal consistency ranged from $\underline{r}=.80$ to $\underline{r}=.84$. Spivack (Note 17) has stated that the reliability of the MEPS instrument would probably be higher if normal populations were utilized. He states the test is reliable and stable over time (see Appendix B).

The MEPS test was scored according to pre-established scoring criteria del ineated by Platt and Spivack (1975). The number of relevant means was scored for each of the ten problens. To accomplish this, two scorers were trained by the experimenter using the P1att-Spivack method. Pilot data gathered in previous studies was used for training purposes. The scoring procedure's reliability and validity were based on the scoring manual and the examples it offered. Inter-rater rel iabil ity was establ ished using 35 questionnaires randomly selected from the sample of 128 . The 35 questionnaires, comprising a total of 350 problems, were scored separately by each rater; the total MEPS score for each questionnaire (number of relevant means for ten problems) was used to compute a rel iability coefficient. The resulting Pearson product-moment rel iability coefficient was $\underline{r}=$ $.96, p<.001$. This establ ishes the inter-rater rel iability for the 
MEPS scoring procedure. The remaining data were divided randomly between each rater for scoring.

The MEPS score consisted of the sum of the relevant means stated for each of the ten stories. The total MEPS score (range 4 to 20) was used as a continuous variable and a categorical variable in the data analysis. The categorical variable was created by tricotomizing the distribution of total scores. Relatively equal groups were generated from the frequency distributions: High problem solvers $(N=49)$ included the total MEPS scores 14 through 20; Middle problem solvers (N = 42) included scores 11 through 13; and Low problem solvers $(N=37)$ included scores 4 through 10 (see Table 6).

Demographic variables.

1. Sex and grade level. The measurement of the student demographic variables of sex and grade level depended upon student self-report on respective questionnaire items.

2. Socioeconomic status. Student socioeconomic status (SES.) was based on the overa11 SES. of the students' parents. This was determined by Hollingshead's Two Factor Index of Social Position (Holl ingshead, Note 16). Students were required to report the ir parents' occupation and education levels (see Appendix A). When the occupation and educational levels between parents differed, the highest relative status for occupation and education was used. From the student report, educational and occupational data were converted to scale scores (7-7) using criteria establ ished by Holl ingshead. Each scale score was then multipl ied by a factor weight; 7 for occupational level; and 4 for educational level. The weights for each factor were previously determined by Hollingshead by the use of multiple correlation 
procedures. The total score obtained by adding the two products, education and occupation scale scores, yielded an index of social position (SES) with a range of 11 to 77 .

The SES. scores were divided into five categories previously established by Hollingshead: Group I included scores 11 to 17; Group II included scores 18-27; Group III included scores 28-43; Group IV included scores 44-60; and Group $V$ included scores 61-77. To establish a three-group categorical variable for data analysis, Groups I ( $\underline{N}=13)$ and II $(\underline{N}=31$ ) were conbined to comprise the upper SES. group ( $\underline{N}=44$; scores 11-27); Group III comprised the middle SES. group ( $N=26$; scores 28-43), and Groups IV $(\underline{N}=43)$ and $V(\underline{N}=15)$ were combined to form the lower SES. group $(\underline{N}=58$; scores $44-77)$. Thus, SES. was divided into upper, middle and lower groups for inter-group comparisons.

\section{Procedure}

The questionnaire was pilot-tested on a group of high school students in order to assess the format, reading level, administrative procedures, and reliability of certain scales. Pilot test data, al ready reported, indicated the soundness of the measure both psychometrically and administratively.

This research project has been reviewed and approved by the assistant superintendent and high school principal of the school involved. Also, the project received approval from the coordinator of Research and Grants, acting for the Institutional Review Board at the University of Rhode Island (see letters in Appendix B).

Students took part in the study only after an explanation of the project was offered by the experimenter and their voluntary consent to 
participate was obtained. The consent from students was obtained verbally. Parental consent was received through the superintendent of school's office: the assistant superintendent gave informed consent (in loco parentis) for the students' participation. Student confidential ity was maintained through the use of numbers to code each questionnaire and teacher/counselor grade rating form. Feedback regarding the results of this study was given to the school administration, and the spec if ic groups and classes involved.

The questionnaire was administered during the mid-fall semester 1980 to groups of $20-25,11$ th and 12th grade students and to groups of 6 to 10, 9th and 10th grade students. Administration of the questionnaire took place during one 50 minute class period at different times during the day depending on which group was scheduled. The experimenter and/or a trained research assistant administered all the questionnaires, provided instructions, and answered any questions during the testing period. Teachers/counselors were not required to stay, al though some did.

Students were told the preceding day by the experimenter that they were chosen to participate in a study of how kids got along in high schoor. A standard statement was read to each group explaining, in general, the nature of the study, the students' right not to participate, and the confidentiality of the results (see Appendix A). Students that did not want to participate told the experimenter at that time. The next day the experimenter administered the questionnaire to students who wished to participate in the study Conly two did not and they were dismissed for the period). Directions were read aloud by the experimenter for each itern or test on the questionnaire. Students who 
understood the instructions went ahead and completed the item. Students with questions were encouraged to ask the experimenter for assistance. Items were administered one at a time until the questionnaire was completed. The experimenter(s) monitored each student carefully to ensure that students understood the instructions and were able to read the items. All students completed each section before the group was allowed to continue.

After the questionnaires were completed each student wrote his/her name and the questionnaire identification number on a piece of paper. The experimenter explained that the students would be rated on acaderic performance by the teacher or counselor in a manner similar to their own self report. Students that did not wish to be rated by the teacher or counselor were told not to put the ir name on the paper. Also, the experimenter explained that when the teacher or counselor rated the students' academic performance the 1 ist with the names and numbers on it was destroyed. The remaining ratings identified the student only by number.

Teachers and counselors rated each student's academic performance using the 13 point rating system. The experimenter was given the ratings for each student and the corresponding identification numbers the next day.

Students, teachers, and counselors were thanked for their participation. Individual feedback regarding the results of the study was given both verbally and in writing to the school administration and the students, teachers, and counselors involved. 


\section{RESULTS}

In this study it is predicted that: (1) social problem solving skills and acaderic and social performance do not vary by sex, grade level or SES.; and (2) high school students with more effective social problem solving skills exhibit higher academic and social performance. In order to test these hypotheses the data were organized into the categories of academic and social performance in schoot, social performance in the community, and probler solving. Descriptive statistics and frequency distributions were calculated for all continuous variables. The demographic variables of sex, SES., and grade level were examined for their relationship with performance (school and community) and problem solving variables using a series of two way ANOVAS (continuous variables) and Chi square statistics (discontinuous variables). The social problem solving categories were al so examined with the demographic variables to determine their relationship to the school and cormunity performance variables using the statistical procedures just del ineated. Significant $F$ scores were tested for homogeneity of variance using Hartley's $F$ max procedure: There were no violations of homogeneity of variance using a probability level of $p<.01$. In the case of unequal groups, the harmonic mean of the number of cases per cell was used to determine the degree of freedom. Further, a 11 significant $F$ scores were analyzed with either a simple effects test (for interaction effects), a student Newman-Keuls procedure (for equal groups), or a Tukey-A test (for unequal groups). A probability level of $\mathrm{p}<.05$ was used for al1 follow-up tests.

The proportion of variance accounted for by a particular variable 
was calculated using the omega square $\left(\boldsymbol{\omega}^{2}\right)$ statistic $\left(\boldsymbol{\omega}^{2}=\underline{F}-1 / \underline{F}\right.$ $+\underline{N}-\underline{J}+1 / \underline{J}-1$ where $\underline{N}=$ the number of cases and $\underline{J}=$ the number of groups). This analys is was performed on all significant $\underline{F}$ values.

The relationship between social problem solving skills and school and cormunity performance was also examined using multiple regression analyses. The highest school and community predictors of problem solving skills are included in two regression equations. The average percentage of variance accounted for each predictor was calculated for both regression equations.

In general, the data supported the hypothes is that there were no demographic differences in problem solving ability and school and community performance. However, grade level and SES. differences were found in certain variables. Similarly, the data supported the hypothes is that effective problem solvers showed higher high school performance than less effective problem solvers. High problem solvers had higher grades and more effective performance on selected social indices. Also, problem solving ability was significantly related to selected community performance indices. Regression equations indicated that there was a highly significant relationship between problem solving skills and school and community performance indices.

In the following discussion of these results, the relationship between the demographic variables and school and community perfomance will be presented first. Next, demographic differences in total problem solving will be presented, followed by problem solving differences across the various school and community performance variables. Finally, the results of the multiple regression analyses and intercorrelations between solving and performance variables will be 
presented.

Demographic results.

To test the first hypothesis, that there are no demographic differences in school and community performance, a series of two-way ANOVAs were computed with each continuous school and community performance variable. Specifically, the following two-way ANOVAs were computed: sex by SES.; sex by grade level; sex by problen solving; SES. by grade level; SES. by problem solving; and grade level by problem solving. In each analys is the sex dimension included male and female groups, the SES. dimension included upper, middle, and lower groups, grade level included freshman, sophomore, junior, and senior groups, and social problem solving included high, middle, and low groups. These two-way ANOVAs were computed with each continuous performance index as a dependent variable. A four-way ANOVA was chosen as the preferred means to obta in the two-way ANOVAs described above. The factorial ANOVA approach simply computed each main effect (sex, SES., grade level, problem solving) once and computed two-way interaction effects (sex by SES.; sex by grade level; sex by problem solving; SES. by problem solving; SES. by grade level; and grade level by problen solving) for each continuous performance index. Three and four-way interactions were suppressed. The factorial ANOVA allows for a more parsimonious data analys is and 1 inits the chance of obtaining an $F$ score by chance. The present section will discuss just the demographic ma in and interaction effects (see Table 3). Problem solving results will be discussed in a later section.

The discontinuous school and community performance variables were 
analyzed with a Chi-square statistic. Specific sex, SES., and grade 1 evel results are presented (see Table 3 ).

Academic performance. The category includes grade point average rating, number of semesters on the honor roll, and post high school training goals. The results for each variable will be presented separately.

1. Grade point average. There were no significant ma in effects for sex and SES. and no significant two way interaction effects for sex by SES. and grade level by SES. A significant ma in effect for grade level $\underline{F}(3,127)=10.89, \underline{p}<.001$ was obtained. Further analys is of this effect with a Newman-Keuls test revealed that the mean g.p.a. rating for sophomores $(M=4.50)$ was significantly higher than the means for freshmen $(\underline{M}=5.69)$, juniors $(\underline{M}=5.88)$, and seniors $(\underline{M}=$ 5.97). There were no significant differences between freshmen, juniors, and seniors in g.p.a. rating. Calculation of the omega square statistic indicated that the grade level effect accounted for $18.8 \%$ of the variance in the g.p.a variable. 


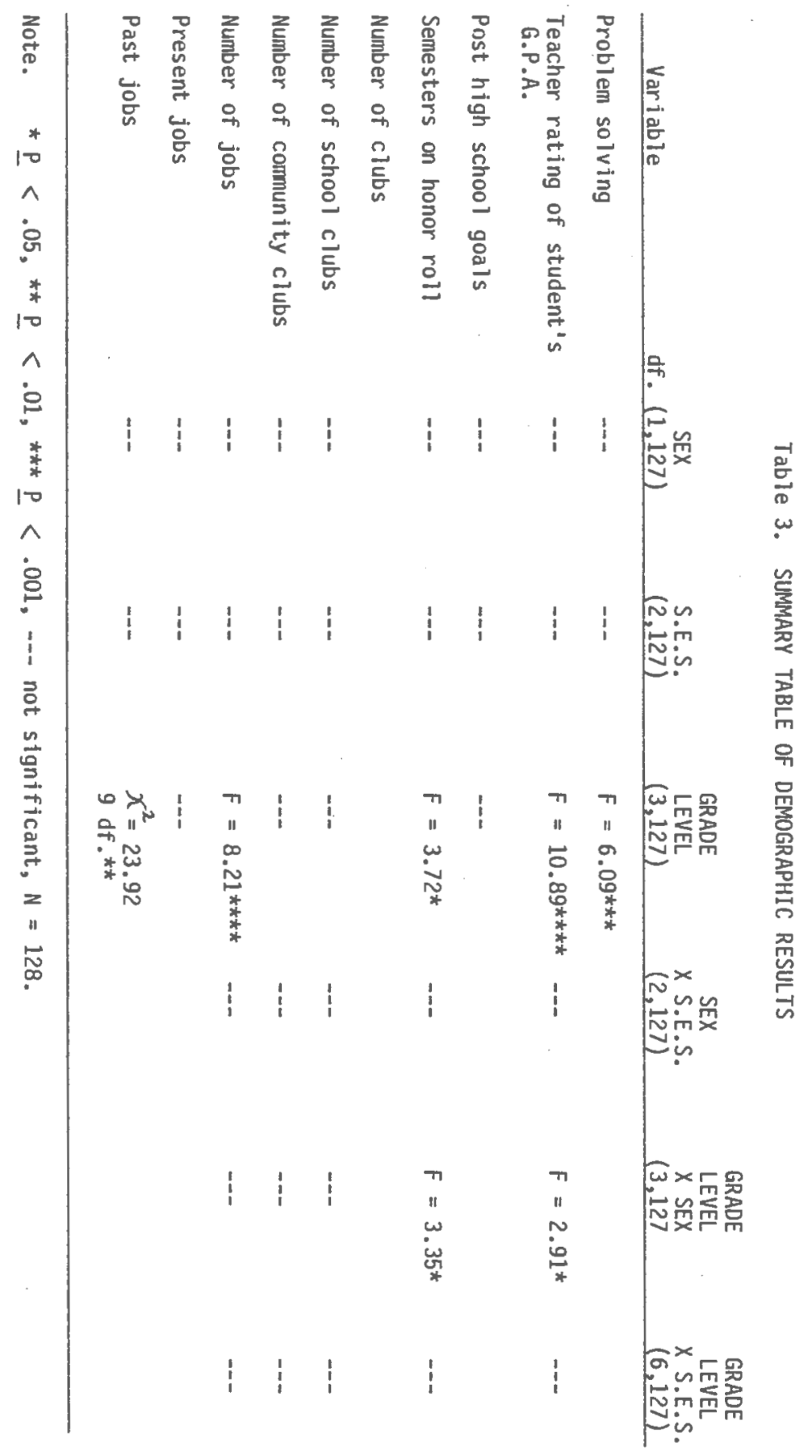




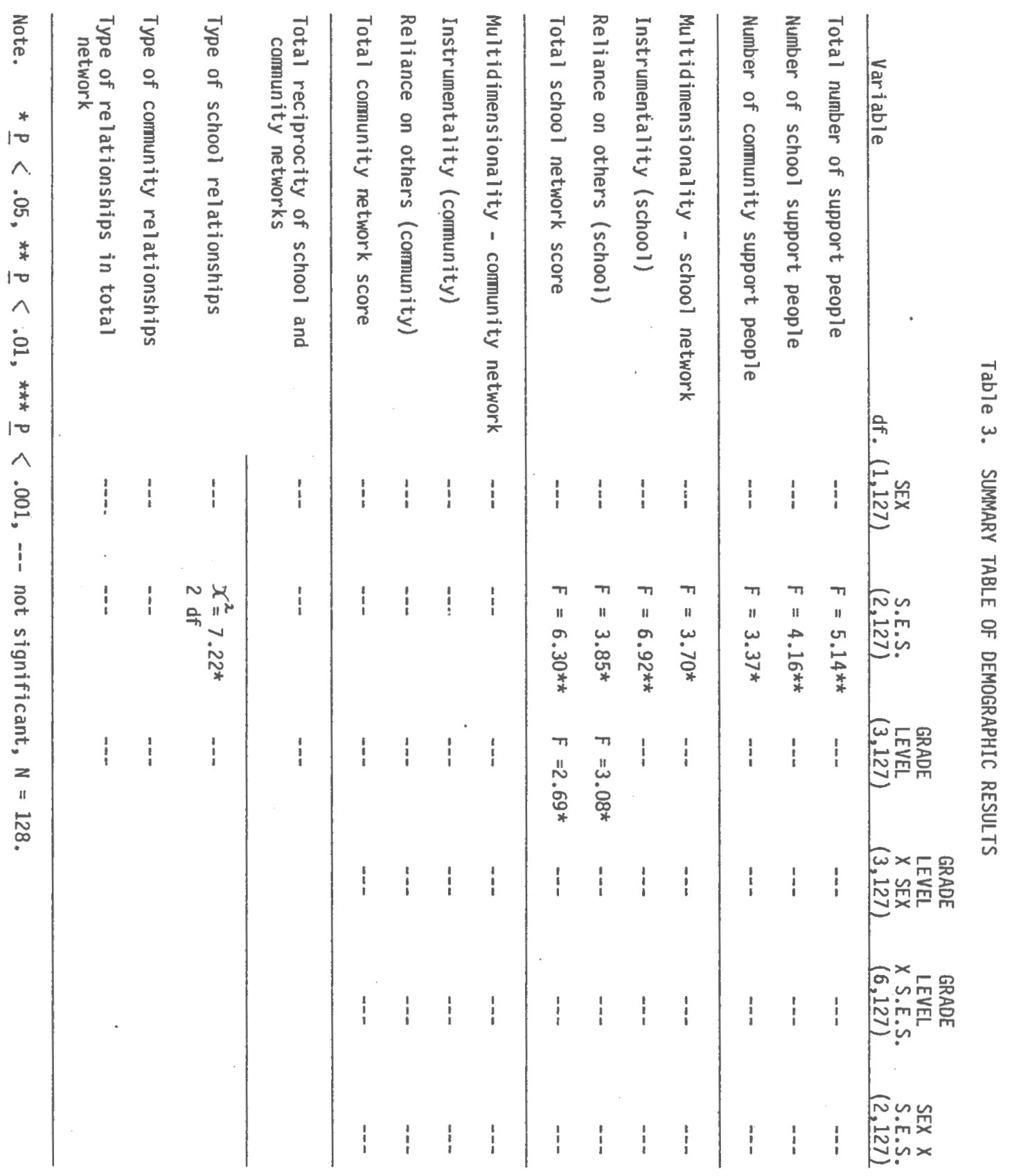


A significant two-way interaction for grade level by sex $\underline{F}(3,127)=$ 2.91, $\mathrm{p}<.05$ was also obtained. The interaction effect accounted for 4.5\% of the total variance for the g.p.a. scores A simple effects test for this interaction found that sophomore males had significantly higher g.p.a. ratings than sophomore females or any other group at any grade level (see Table 4). Sophomore females had significantly higher g.p.a. ratings than freshmen males, junior males and females, and senior males and females.

Table 4. Mean G.P.A. ratings for sex and grade level groups

\begin{tabular}{lccccc} 
Sex & Freshmen & Sophomore & Junior & Senior & Total \\
\hline Male & 6.00 & 4.13 & 6.00 & 6.13 & 5.56 \\
Female & 5.38 & 4.88 & 5.75 & 5.83 & 5.45 \\
Comb ined Group & 5.69 & 4.50 & 5.88 & 5.98 & $\ldots$ \\
\hline
\end{tabular}

Note: $N=128$ for total sample; $N=64$ for each sex; $N=32$ for each grade level (16 male, 16 female).

2. Number of semesters on the honor roll. There were no significant ma in effects for sex or SES. and no significant two-way interaction effects for sex by SES. and SES. by grade leve1. A significant ma in effect for grade level $E(3,127)=3.72, p<.05$ was obtained. The grade level effect accounted for $5.9 \%$ of the total variance for this variable. A Newman-Keuls follow-up tested revealed that sophomores $(M=2.41)$ were on the honor roll the preceding year significantly more often than freshmen $(\underline{M}=.97)$ and juniors $(\underline{M}=$ 1.19), but not more often than seniors $(\underline{M}=1.50)$. Freshmen, junior, and senior mean scores did not differ significantly. A significant two-way interaction effect for sex by grade level $\underline{F}(3,127)=3.35, p<$ .05 was obtained. The interaction effect accounted for $4.3 \%$ of the 
total variance for this variable. A simple effects test found that sophomore males were on the honor roll significantly more often than sophomore females or any other group at any other grade level (see Table 5). Also, sophomore females were on the honor roll significantly more frequently than freshman males.

Table 5. Mean number of semesters on the honor roll for sex and grade level groups

Sex Freshmen Sophomore Junior Senior Total

\begin{tabular}{lrrrrr} 
Male & 0.63 & 3.00 & 1.25 & 1.50 & 1.59 \\
Female & 1.31 & 1.81 & 1.25 & 1.50 & 1.44 \\
Combined Group & .97 & 2.41 & 1.19 & 1.50 & $\ldots$ \\
\hline
\end{tabular}

Note: $N=128$ for total sample; $N=64$ for each sex; $N=32$ for each grade level ( 16 male, 16 female).

3. Post high school training goals. The Chi-square analysis revealed no significant main effects for sex, SES., and grade level.

In summary, academic performance varied somewhat by grade level with sophomore male and female students showing higher g.p.a. ratings, and more semesters on the honor roll than other grade level groups. The 1 inited demographic differences found in acadenic performance are consistent with original predictions. The disparity between sophomores' academic performance and other grade levels is not consistent with the null hypothesis.

Social performance-school/comunity. This category includes the school performance variables of club participation and school social network (number support people, multidimensional ity, instrumental ity, rel iance on others, reciprocity, type of relationship, and total network score. The community performance variables of jobs, clubs, and 
community social network are also included. The performance variables of club participation and social network have both school and community components and will be presented together for simpler comparison of the ANOVA and Chi-square results. (See Table 6 for mean scores.).

1. Clubs. This variable was divided into total number of clubs, number of school clubs, and number of community clubs for analys is. Each of these variables was used as a dependent variable in separate ANOVAs to determine whether there were demographic differences. There were no significant ma in or two-way interaction effects for total number of clubs, number of school clubs, or number of comunity clubs.

In general, students were more involved in school than cormunity clubs and tended to be involved in at least one club somewhere. For this sample, ciub participation does not appear to be related to demographic variables.

2. Jobs. The continuous dependent variable, total number of jobs, was examined using a series of two-way AllOVAS. The discontinuous variables, past jobs, and present jobs each included the categories: no job; sumer job onty; part-time/year-round-oniy; and both sumer and part-time/year-round and were analyzed with a Chi square statistic. There were no significant relationships between any of the demographic variables (sex, SES., grade level) and the present job categories. Also, there were no significant relationships between sex and SES., and the past job categories. Final1y, no main effects for sex or SES. and no two-way interaction effects were obtained with total number of jobs. A significant main effect for grade level was obtained for total number of jobs $\underline{F}(3,127)=8.21, p<.001$. A subsequent anatys is of this effect with a Newman-KeuTs procedure indicated that the mean 
number of total jobs held by seniors $(\underline{M}=2.06)$ was significantly higher than the mean number of total jobs held by freshmen $(M=1.03)$, sophomores $(M=1.09)$, and juniors $(M=1.00)$. There were no significant differences in the mean number of total jobs held by freshmen, sophomores, and juniors. The grade level effect, analyzed with an omega square statistic, accounted for $14.4 \%$ of the total variance in the variable, number of jobs. Grade level was also significantly related to the variable past jobs $\chi^{2}(9)=23.92, \mathrm{p}<$ .01. A further analys is of this relationship revealed that a sign if icant number of seniors had both sumer and part-time/year-round jobs versus those students with part-time, summer, or no jobs.

A subsequent analys is of the differences between the present job categories showed that significantly more students have either no job or a year-round job than students who have part-time and summer jobs $X^{2}(3)=26.25, \mathrm{p}<.001$. Specifically, 28\% of the total sample (present job category) have no jobs; $16 \%$ have a summer job only; $14 \%$ have a part-time job; and $42 \%$ have a year-round job. Most of the students in the sample presently hold a year-round job.

Similarly, the past job variable was also analyzed for the total differences between categories. A significant number of students had either no job or a year-round job in the past as compared with those who had part-time or summer jobs in the past $\chi^{2}(3)=41.84, p<.001$ (tota) sample, no job $=41 \%$; part-time $=7 \%$; summer $=16 \%$; year-round $=$ $36 \%)$.

When the total sample was divided into the categories job or no job for both past and present (instead of 4 categories) it was found that more students presently have jobs than those who do not $x^{2}(1)=$ 
24.50, $\mathrm{p}<.001$ (72\% have jobs, $28 \%$ do not). In the past jobs category, there was no significant difference between the number of students who had a job versus those who did not ( $59 \%$ had jobs, $41 \%$ did not). When both past and present job categories were collapsed, it was found that a significant number of students have or did have a job versus those who do not have and never had a job $\chi^{2}(1)=23.76, \mathrm{p}<.001(65 \%=$ job anytime, $35 \%=$ no job anytime).

3. Social networks. The social networks of school and community are organized al ong various dimensions. Each network variable is taken as a dependent variable and analyzed by demographic groups with a series of two-way ANOVAs (continuous variables) or a Chi-square procedure (discontinuous variables).

a. Number of support people. This variable was analyzed by the total number of support people (the total number of different support people listed), number of school support people listed, and the number of community support people listed. Two-way ANOVAs yielded no main effects for sex or grade level and no two-way interaction effects for the total number of support people, the number of school support people, and the number of community support people listed. However, there was a main effect for SES. for each of the support person variables of total $\underline{F}(2,127)=5.14, \underline{p}<.01$, school $\underline{F}(2,127)=4.16, \underline{p}<$ .01 , and community $\underline{F}(2,127)=3.37, \underline{p}<.05$. The SES. effect accounted for $6.1 \%$ of the total support person score, $4.7 \%$ of the school support person score, $3.6 \%$ of the community support person score. Upper SES. students had more support people 1isted (school, $\underline{M}=3.89$; community, $\underline{M}=3.80$; total, $\underline{M}=6.75)$ than middl e SES. students (school, $\underline{M}=3.46$; community, $\underline{M}=3.27$; total, $\underline{M}=5.58$ ), but not more 
than lower SES. students (school $\underline{M}=3.60$; community, $\underline{M}=3.64$; total, $\underline{M}=6.27)$. Middle and lower SES. students did not differ significantly in the number of support people listed.

b. Multidimensionality. This variable was comprised of the number of school and community support relationships that gave or received support in more than one category (emotional, material, recreational). Multidimensionality was analyzed separately for school and community networks by a series of two-way ANOVA statistics. There were no significant main effects for sex or grade level and no significant two-way interaction effects for the variables of multidimensionality-school. Also, there were no main or two-way interaction effects for the variable, multidimensionality-community.

A significant main effect for SES. $F(2,127)=3.70, p<.05$ was obtained for the dependent variable multidimensionality-school. The SES. effect accounted for $4.0 \%$ of the total variance for this variable. Further analysis of this effect showed that upper SES. students $(\underline{M}=3.82)$ had significantly higher multidimensionality scores on their school network than their lower and middle SES. counterparts $(\underline{M}=3.43$ and 3.46 , respectively). Lower and middle SES. students did not differ significantly along this dimension.

c. Instrumentality. Instrumentality, others reliance on the student for emotional, material, or recreational support, was analyzed separately for the school and community social networks. Two-way ANOVAs with instrumentality-school as the dependent variable yielded no significant two-way interaction effects. A similar analysis with instrumentality-community revealed no significant main or two-way interaction effects. 
A significant main effect for SES. $(\underline{F}(2,127)=6.92, p<.01$ was obtained with instrumentality-school as the dependent variable. The SES. effect accounted for $8.5 \%$ of the total variance for this variable. Further analysis with a Tukey A procedure indicated that upper SES. students had significantly higher instrumentality scores $(\underline{M}=10.48)$ than lower SES. students $(\underline{M}=8.45)$, but not more than midd7e SES. students $(\underline{M}$ =9.31). Middle SES. and lower SES. students did not differ significantly in instrumentality scores.

d. Reliance. Reliance on others was also analyzed separately for school and community networks. There were no significant main or interaction effects for the dependent variable reliance-comunity. Also, there was no significant main effect for sex and no significant interaction effects for the variable reliance-school. Significant main effects for SES. $F(2,127)=3.85, \underline{p}<.05$ and grade level $\underline{F}(3,127)=$ $\mathrm{p}<.05$ were obtained for reliance-school. The SES. and grade level effects accounted for $4.3 \%$ and $4.8 \%$, respectively, of the total variance for the reliance scores. The SES. main effect, analyzed using a Tukey $A$ procedure indicated that upper SES. students $(\underline{M}=10.23)$ had significantly higher school work reliance scores than lower SES. students $(\underline{M}=8.84)$, but not significantly higher than middle SES. students $(\underline{M}=$ 9.12) $(\mathrm{p}<.05)$. Again, middle and lower SES. students did not differ significantly al ong this dimension.

The main effect for grade level was analyzed with a Newman-Keuls test because of equal group sizes $(N=32)$. Sophomores $(\underline{M}=10.19)$, juniors $(\underline{M}=9.66)$, and seniors $(\underline{M}=9.75)$ had significantly higher reliance scores than frestmen $(\underline{M}=7.91)$. Sophomores, juniors, and seniors did not differ significantly from each other in their mean reliance scores. 
e. Total network score. There were no significant main or interaction effects when the total community network score was analyzed. Further, there was no significant main effect for sex and no significant interaction effects when the total school network was analyzed. Significant main effects for SES. $\underline{F}(2,127)=6.30, \mathrm{p} \angle .01$ and grade level $\underline{F}$ $(3,127)=2.69, \mathrm{p}<.05$ were obtained for the total school network score. The SES, and grade level effects accounted for $7.6 \%$ and $3.8 \%$, respectively, of the total variance for the total school network score. A further analysis of the SES. main effect indicated that upper SES. students $(\underline{M}=20.68)$ had significantly higher total school network scores than lower SES. students $(\underline{M}=18.42)$. Middle and lower SES. students did not have significantly different mean scores for the total school network.

A Newman-Keuls test for the grade level main effect revealed that sophomores $(\underline{M}=19.94)$, juniors $(\underline{M}=19.25)$, and seniors $(\underline{M}=19.25)$ did not differ significantly from each other, but they all had significantly higher total school network scores than did freshmen students $(\underline{M}=16.06)$ $(\mathrm{p}<.05)$.

f. Reciprocity. Reciprocity, the balance between social network support given and support received, was divided in the categories reciprocal and nonreciprocal and analyzed for demographic effects with a Chi-square statistic. Separate analyses for the school, community, and total support networks revealed no significant relatonships between reciprocity and any of the demographic variables.

g. Type of support relationship. The type of support relationship listed (peer, adult) was analyzed for demographic effects using a Chi-square statistic. There were no significant associations between 


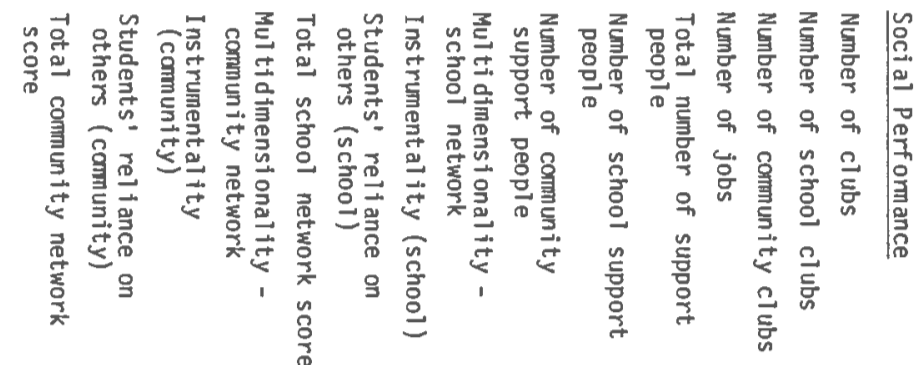

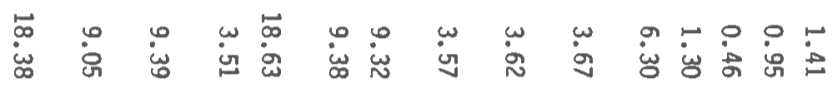

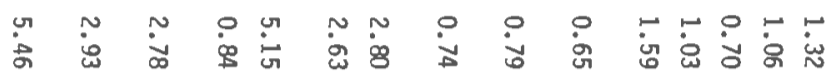

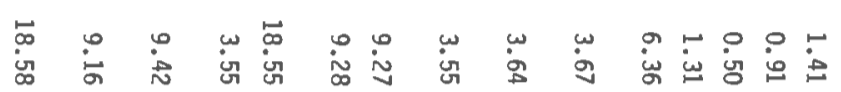

尚

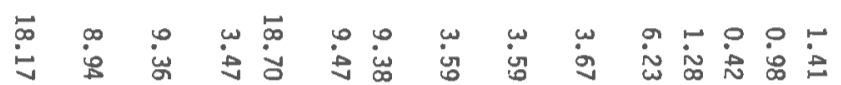

岀

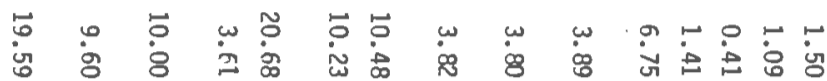

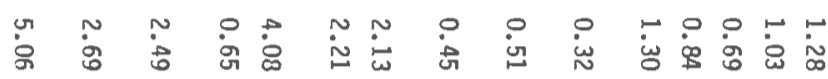

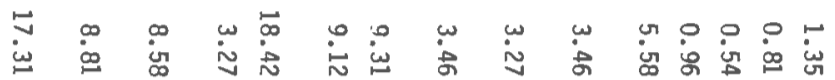

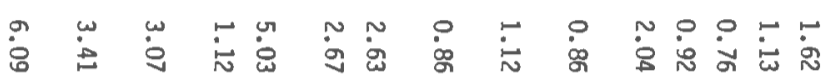

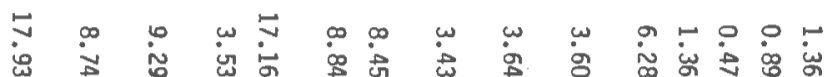

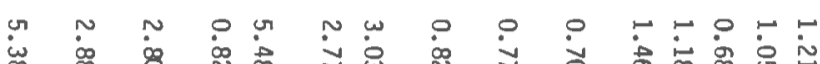

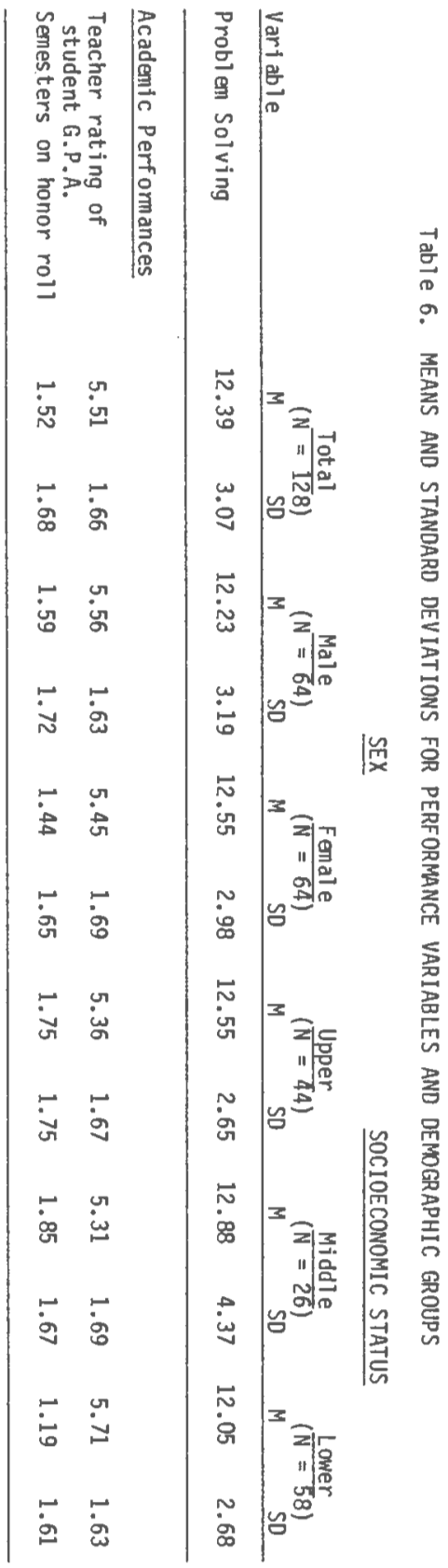




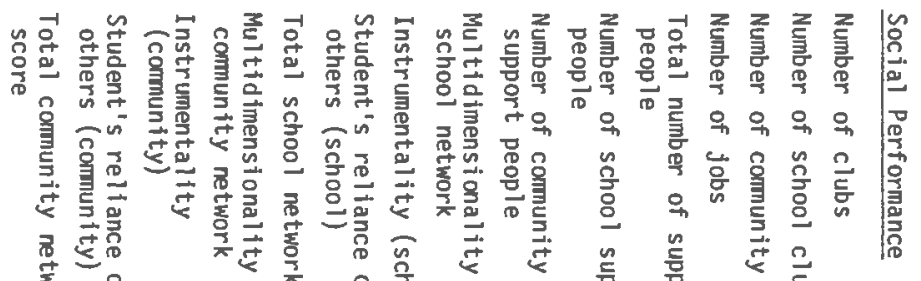

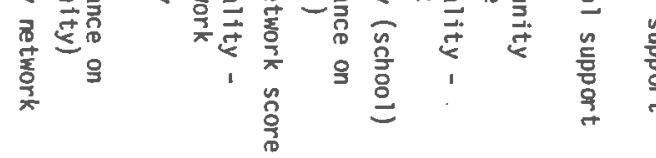

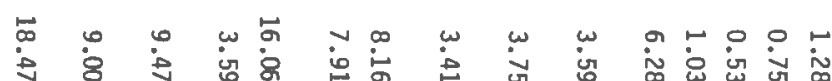

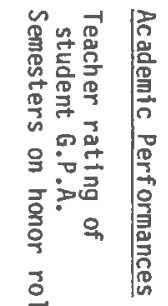

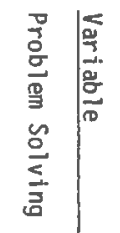

芯

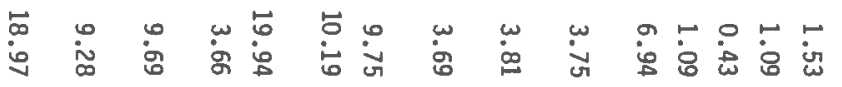

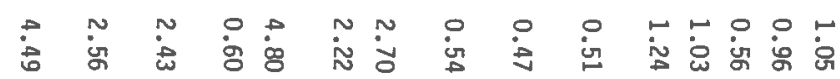

㭊

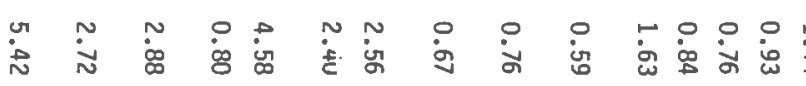

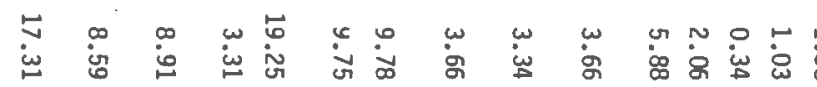

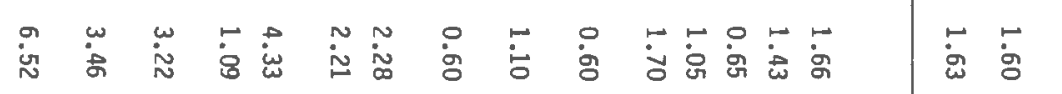


Table 6 MEANS AND STANDARD DEVIATIONS FOR PERFORMANCE VARIABLES AND PROBLEM SOLVING GROUPS

PROBLEM SOLVING

Variable $\quad M^{\left(N^{\frac{\text { High }}{=4}}\right)}$ SD $\quad M^{\left(\frac{\text { Middle }}{(N=42)}\right.} S D \quad M^{\left(N^{\text {Low }}=37\right)} S D$

Academic Performances

\begin{tabular}{|c|c|c|c|c|c|c|}
\hline $\begin{array}{l}\text { Teacher rating of } \\
\text { student G.P.A. } \\
\text { Semesters on honor roll }\end{array}$ & $\begin{array}{l}4.35 \\
2.78\end{array}$ & $\begin{array}{l}1.45 \\
1.56\end{array}$ & $\begin{array}{l}5.81 \\
1.07\end{array}$ & $\begin{array}{l}1.17 \\
1.31\end{array}$ & $\begin{array}{l}6.70 \\
0.35\end{array}$ & $\begin{array}{l}1.37 \\
1.01\end{array}$ \\
\hline \multicolumn{7}{|l|}{ Social Performance } \\
\hline Number of clubs & 1.65 & 1.41 & 1.14 & 1.22 & 1.38 & 1.28 \\
\hline Number of school clubs & 1.16 & 1.20 & 0.76 & 1.05 & 0.86 & 0.82 \\
\hline Number of community clubs & 0.49 & 0.71 & 0.38 & 0.62 & 0.51 & 0.77 \\
\hline Number of jobs & 1.55 & 1.10 & 1.19 & 1.02 & 1.08 & 0.89 \\
\hline $\begin{array}{l}\text { Total number of support } \\
\text { people }\end{array}$ & 6.65 & 1.47 & 6.07 & 1.57 & 6.08 & 1.72 \\
\hline $\begin{array}{l}\text { Number of school support } \\
\text { people }\end{array}$ & 3.76 & 0.52 & 3.60 & 0.66 & 3.65 & 0.79 \\
\hline $\begin{array}{l}\text { Number of cormunity } \\
\text { support people }\end{array}$ & 3.59 & 0.93 & 3.57 & 0.70 & 3.70 & 0.70 \\
\hline $\begin{array}{l}\text { Multidimensionality - } \\
\text { school network }\end{array}$ & 3.71 & 0.54 & 3.57 & 0.67 & 3.38 & 0.98 \\
\hline Instrumentality (school) & 9.88 & 2.58 & 8.86 & 2.76 & 9.11 & 3.06 \\
\hline $\begin{array}{l}\text { Students' reliance on } \\
\text { others (school) }\end{array}$ & 10.33 & 2.13 & 9.00 & 2.42 & 8.54 & 3.08 \\
\hline Total school network score & 20.18 & 4.54 & 17.67 & 4.77 & 17.65 & 5.91 \\
\hline $\begin{array}{l}\text { Multidimensionality - } \\
\text { cormunity network }\end{array}$ & 3.57 & 0.94 & 3.50 & 0.71 & 3.43 & 0.87 \\
\hline $\begin{array}{l}\text { Instrumenta) ity } \\
\text { (community) }\end{array}$ & 9.61 & 2.90 & 9.36 & 2.64 & 9.14 & 2.84 \\
\hline $\begin{array}{l}\text { Students' reliance on } \\
\text { others (community) }\end{array}$ & 9.71 & 3.03 & 8.98 & 2.55 & 8.24 & 3.08 \\
\hline $\begin{array}{l}\text { Total community network } \\
\text { score }\end{array}$ & 19.37 & 5.71 & 18.10 & 4.92 & 17.38 & 5.62 \\
\hline
\end{tabular}


type of relationship and the demographic variables sex and grade level. A significant effect for type of rel ationship and SES. was obtained $X^{2}(1)=7.22, p<.01$. Upper SES. students had significantly more adult relationships than lower SES. students. There were no significant differences between middle and upper and middle and lower SES: students. Also of note, was the fact that most of the support relationships (89\%) fell into the category of peer.

To summarize, community networks did not vary by demographic variables. These results are consistent with original predictions. There were 1 imited demographic differences in the school network indices. In general, school networks varied by socioeconomic status with upper SES. students having more network properties than either middle or lower SES. students. Specifically, the socioeconamic differences can be summarized as follows: a) upper SES. students had more support people than middle SES. students, but not more than lower SES. students; b) upper SES. students had greater multidimensionality to their network than middle or lower SES. students; and c) upper SES. students had greater instrumentality (others' reliance on them), reliance on others, and total school network scores than lower SES. students, but not greater than middle SES. students. These socioeconamic differences are contrary to initial predictions in the first hypothesis.

Grade level differences in school social networks were found al ong the dimensions of reliance on others and total network score. Sophomores, juniors and seniors consistently had more school network properties and relied more heavily on others for material, emotional and recreational support than freshmen students. This is contrary to the predictions offered in the first hypothesis. 
The community network had overall mean scores similar to the school network scores yet the former had almost no differences by sex, SES., problem solving, or grade level. Only the number of community support people listed showed any variance by demographic variables; upper SES. students had more support people in the community than middle SES. students, but not more than lower SES. students. It should be noted that both school and community networks did not include family members.

\section{Problem Solving Results}

As a further test of the first hypothesis, that there will be no demographic differences in problem solving and school performance, a a series of two-way ANOVAs (sex by grade 1 evel, sex by SES., SES. by grade level) were computed with problem solving (MEPS score) as the dependent variable. There were no significant main effects for sex or SES. and no significant two-way interaction effects. There was a significant main effect for grade leve $\mathrm{E}(3,127)=6.09, \mathrm{p} \angle .001$. The grade 1 eve 1 effect accounted for $10.7 \%$ of the total variance for the problem solving scores. A Newman-Keuls follow-up test showed that freshmen students $(\underline{M}=$ 10.69) had significantly lower problem solving scores than sophomores ( $\underline{M}$ $=13.41)$, juniors $(\underline{M}=12.22)$, and seniors $(\underline{M}=13.25)$. The mean scores for sophomores, juniors, and seniors did not differ significantly from each other (see Table 6). These 1 imited demographic differences offer further support for the first hypothesis.

The prediction that effective problem solvers will perform better in school, was tested with a series of two-way ANOVAs and Chi-square analyses. As previously described; the problem solving score was trichotomized to create high, medium, and low problem solving groups. 
Problem solving was then included as an independent variable with the demographic variables of sex, SES. and grade level as each school and performance variable was analyzed. The problem solving differences in school and community performance variables will be presented next.

There were no significant main or two-way interaction effects for problem solving and the following variables: (1) number of clubs (total, school, community); (2) post high school training goals; (3) jobs (total number jobs, present jobs); and (4) social network (total number support people, number of school support people, number of community support people, multidimensionality-school and community, instrumentality-school and cammunity, total network score-school and community, type of support rel ationship).

Significant problem solving differences were found with selected school and community performance indices. Specifically, a significant main effect for problem solving was revealed with grade point average $\underline{F}$ $(2,127)=43.15, \underline{p} \angle .001$ and number of semesters on the honor roll $\underline{F}$ $(2,127)=33.69 \mathrm{p}<.001$ (see Table 7$)$. The problem solving effect accounted for $39.7 \%$ of the variance in g.p.a. and $33 \%$ of the variance in number of semesters on the honor roll. Further analysis of the problem solving effects with a Tukey A procedure indicated that high problem solvers had a significantly higher mean grade point rating $(\underline{M}=4.35)$ and were on the honor roll the preceding year significantly more often $(\underline{M}=$ 2.78) than middle problem solvers (g.p.a. $\underline{M}=5.81$; honor roll $\underline{M}=1.07$ ) and 1 ow problem solvers (g.p.a. $\underline{M}=6.70$; honor roll $\underline{M}=.35$ ). Middle problem solvers had significantly higher g.p.a. ratings than low problem solvers. Middle and low problem solvers did not differ significantly for number of semesters on the honor roll. 
Table 7. SUMMARY TABLE OF PROBLEM SOLVING RESULTS

\begin{tabular}{|c|c|c|c|c|}
\hline Variable & $\begin{array}{c}\text { Problem } \\
\text { Solving } \\
\text { df. }(2,127) \\
\end{array}$ & $\begin{array}{l}\text { Grade } \\
\text { Level } \times \\
\text { Problem } \\
\text { Solving } \\
(6,127) \\
\end{array}$ & $\begin{array}{l}\text { Sex } x \\
\text { Problem } \\
\text { Solving } \\
(2,127)\end{array}$ & $\begin{array}{l}\text { S.E.S. } x \\
\text { Problem } \\
\text { Solving } \\
(4,127) \\
\end{array}$ \\
\hline Teacher rating of student G.P.A. & $F=43.15^{\star \star \star \star \star}$ & $-\cdots$ & --- & $F=2.96 \star$ \\
\hline Post high school goals & -- & & & \\
\hline Semesters on honor roll & $F=33.69 \star \star \star \star$ & --- & $F=3.51 *$ & --- \\
\hline Number of clubs & --- &.-- & --- & -- \\
\hline Number of school clubs & --- & --- & -- & -- \\
\hline Number of comunity clubs & --- & --- & -- & --- \\
\hline Number of jobs & $\cdots$ & -- & -- & $\cdots$ \\
\hline Present jobs & $\cdots$ & & & \\
\hline Past jobs & $\begin{array}{l}X^{2}=16.40 \\
6 \mathrm{df} . *\end{array}$ & & & \\
\hline
\end{tabular}

Note. $\quad * \underline{p}<.05, \star \star \underline{p}<.01, \star \star \star \underline{p}<.001, \ldots$ not significant, $N=128$. 
Table 7 SUMMARY TABLE OF PROBLEM SOLVING RESULTS (CONT'D)

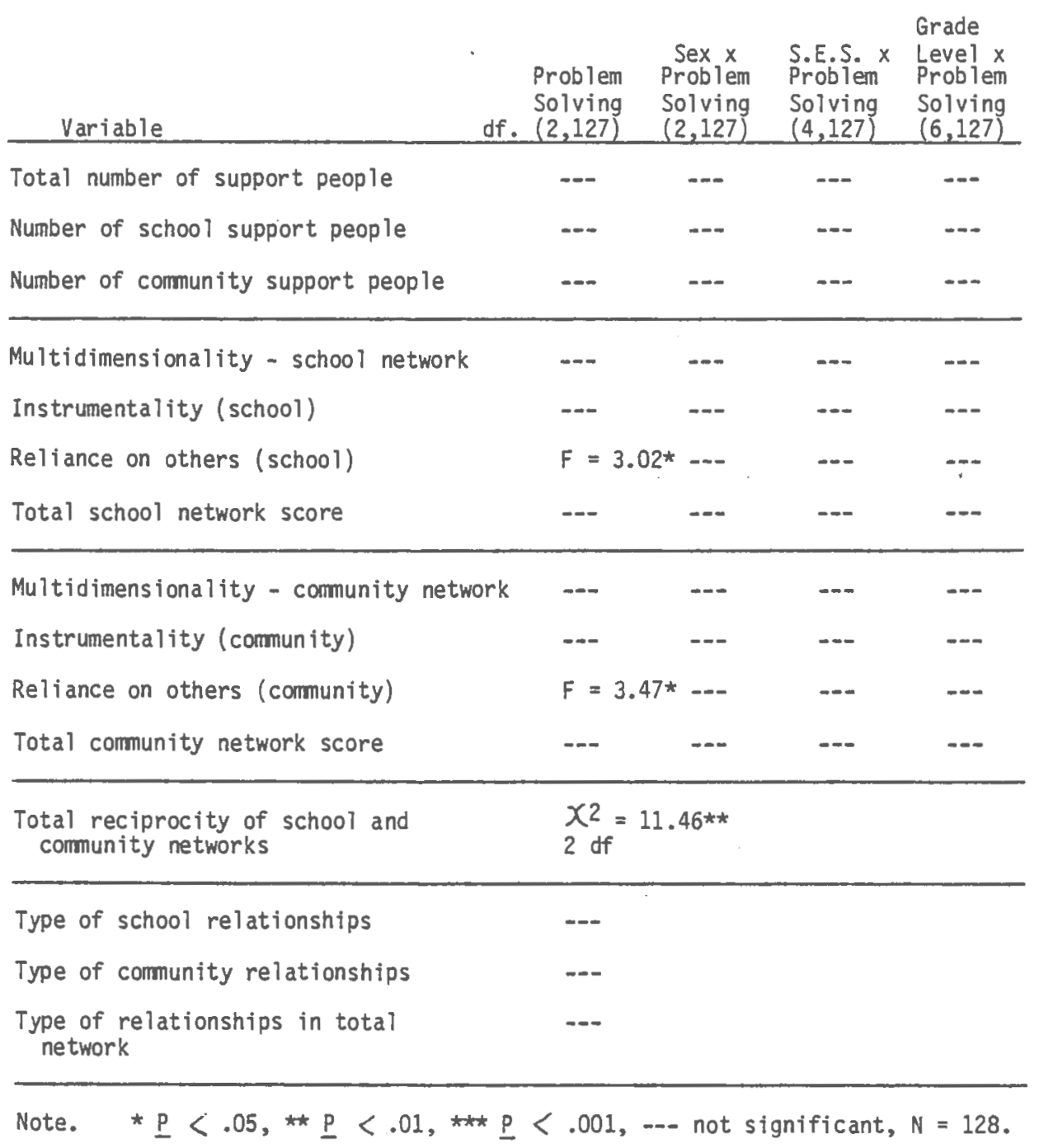


A significant two-way interaction effect of SES. by problem solving $F$ $(3,127)=2.91, p<.05$ was obtained for g.p.a. ratings. The interaction effect accounted for $4.3 \%$ of the total variance for g.p.a. A simple effects test found that upper SES., high problem solvers $(\underline{M}=3.88)$ had significantly higher g.p.a. ratings than low SES., high problem solvers $(\underline{M}=4.68)$ or any other group (see Table 8).

Table 8. Mean G.P.A. ratings for SES and problem solving groups SES. High Middle Low Total

Upper

3.88 $(\mathrm{N}=17)$ 6.21 $(\mathrm{N}=14)$

6.38

$(\mathrm{N}=13)$ 5.36

Middle

$(N=13) \quad(N=6)$

Low

4.68

$(N=19)$

5.86

$(\mathrm{N}=22)$

5.75

$(\mathrm{N}=7)$

6.65

$(\mathrm{N}=17)$

5.81

$(\mathrm{N}=42)$
6.70

$(\mathrm{N}=37)$
Combined Group

$$
\begin{gathered}
4.35 \\
(N=49)
\end{gathered}
$$

A significant two-way interaction effect of sex by problem solving $F(2,127)=3.51, p<.05$ was obtained for number of semesters on the honor roll. The interaction effect accounted for $5.2 \%$ of the total variance for this variable. A simple effects test indicated that both male and female high problem solvers were on the honor roll significantly more of ten than male and female middle and low problem solvers. Also, male, middle problem solvers were on the honor roll significantly more of ten than female, low problem solvers (see Table 9). 
Table 9. Mean number of semesters on the honor roll for sex and problem solving groups

\begin{tabular}{lcccc} 
Sex & High & Middle & Low & Total \\
Male & 2.74 & 1.27 & .58 & 1.59 \\
Female & $(N=23)$ & $(N=22)$ & $(N=19)$ & $(N=64)$ \\
& $(N=26)$ & $(N=20)$ & $(N=18)$ & $(N=64)$ \\
Combined Group & $(N=78$ & 1.07 & .35 & .35 \\
& $(N=49)$ & $(N=42)$ & $(N=37)$ & \\
\hline
\end{tabular}

A Chi-square analysis for past jobs (no job, summer, part-time/yearround, both part-time/year-round and summer) by problem solving yielded a significant relationship between these two variables $\chi^{2}(6)=16.40$, $\mathrm{p}<.05$. Further analysis of this relationship showed that significantly more high problem solvers had year-round jobs than middle and low problem solvers. Also, high problem solvers had significantly more year round jobs than no jobs, part-time, or summer jobs. (No job $=28 \%$; summer $=$ $10 \%$; both $=45 \%$.

Problem solving groups differed significantly in their performance on one dimension of the social network measure. A significant main effect for problem solving was found with the variable reliance on others for both the school network $\underline{F}(2,127)=3.02, \underline{p}<.05$ and the community network $E(2,127)=3.47, \underline{p}<.05$. The problem solving effect accounted for $3.1 \%$ of the total variance in the reliance-school variable and $3.7 \%$ of the total variance in the reliance-community variable. A Tukey $A$ procedure indicated that high problem solvers had significantly higher reliance scores ( school network, $\underline{M}=10.33$; community network, $\underline{M}=9.71$ ) than middle problem solvers (school network, $\underline{M}=9.00$; community network, $\underline{M}=8.97$ ), and low problem solvers (school network, $\underline{M}=8.54$; community 
network, $\underline{M}=8.24)$. Middle and low problem solvers did not differ significantly from each other in their mean reliance scores. Thus, high problem solvers seemed to rely more on their peers for support than did their middle and 1 ow problem solving counterparts.

A significant relationship was found between problem solving and reciprocity of support relationships $X^{2}(1)=11.46, p<.01$. Further analysis of this result revealed that high problem solvers had significantly more reciprocal relationships than did middle and low problem solvers. Middle and low problem solvers did not differ significantly on this dimension.

As a further analysis of the reciprocity variable the school and cormunity network relationships were examined separately. A significant associationship was found between problem solving and reciprocity for both school $X^{2}(1)=12.47, \mathrm{p}<.01$ and community $X^{2}(1)=11.94, \mathrm{p}<$ .01 relationships. In both networks high problem solvers had significantly more reciprocal relationships than did middle and low problem solvers. Middle and low problem solvers did not differ from each other in either the school or community reciprocity analyses. The total reciprocity frequency table was divided into total reciprocal relationships versus nonreciprocal rel ationships for further comparison. There were significantly more reciprocal relationships (72\%) than nonreciprocal relationships (28\%) $x^{2}(1)=262.11, \underline{p}<.001$ (Total $\left.N=970\right)$.

In sumary, problem solving differences in academic performance and social performance offer support for the second hypothesis. High problem solvers: (1) received higher g.p.a. ratings; (2) were on the honor roll more of ten 1 ast year; (3) had more year-round jobs in the past; (4) relied more heavily on peers for emotional, material, and recreational support, 
and (5) had more reciprocal support relationships than middle or low problem solvers. For the most part, middle and low problem solvers did not differ significantly in academic and social performance.

The next sections offer a further test to the second hypothesis and discuss the more general relationships that exist between the continuous school and community performance variables and problem solving scores. First, Pearson product-mament correl ation coefficients are presented between problem solving skills, school performance, and community performance. Second, the inter-correlations between the total problem solving score and the ten stories that comprise the MEPS test are presented. Finally, separate multiple regression analyses are presented for problem solving and school performance and problem solving and cormunity performance to highlight the most important predictors of problem solving skills.

Intercorrelation of problem solving and performance variables

Pearson product-mament correlation coefficients were computed between the continuous variable of problem solving and school and community performance variables (see table 10). Specifically, problem solving is significantly related to grade point average $\underline{r}=.44, p<.001$, number of semesters on the honor roll $\underline{r}=.60, \underline{p}<.001$, club participation $\underline{r}=$ $.16, \underline{p}<.05$, number of jobs $\underline{r}=.22, \underline{p}<.01$, school network measures $\underline{r}$ $=.23$ to .40 , and community network indices $\underline{r}=.19$ to .31 . Although the correlations $\underline{r}=.22, \underline{r}=.16, \underline{r}=.23, \underline{r}=.19$ are statistically significant, they are not practically significant because they account for relatively little of the total variance. These positive correlations suggest that a strong problem solving component is found in many of the school and community performance indices. These data also support the 
second hypothesis.

Pearson product-monent correlation coefficients were al so computed for each of the 10 MEPS problems and the total score $(N=128)$. Correlations between each of the stories and the total MEPS score ranged from $\underline{r}=.36$ to $\underline{r}=.64$. Stories one $(\underline{r}=.64)$, three $(\underline{r}=.59)$, and four $(\underline{r}=.54)$ had the highest intercorrel ations with the total MEPS score. Each story seems to have a relatively independent contribution to the total score according to the intercorrelation matrix presented in Table 11. Individual story intercorrelations ranged from a high of $\underline{r}=$ .37 to a low of $\underline{r}=-.03$.

A significantly positive relationship was found between grade point average and number of semesters on the honor roll $\underline{r}=.71, p<.001$ (as might be expected) and the total support people listed on social networks $\underline{r}=.15, \underline{p}=\angle .05$. Number of semesters on the honor roll rel ated significantiy to most of the school and community network indices $\underline{r}=.18$ to $\underline{r}=.26$ (see Table 10 for specific correl ations). Although the correlations $\underline{r}=.15, \underline{r}=.18, \underline{r}=.26$ are statistically significant they account for such a small portion of the total variance that they are practically insignificant. These data suggest that there is a relatively strong relationship between academic performance and school and community performance as measured by the development of social networks.

Number of clubs, an index of student involvement, was found to be significantly related to al 1 the school and community network variables $\underline{r}$ $=.16$ to $\underline{r}=.29$ (see Table 10 for specific correl ations). However, the correlations in the $\underline{r}=.16$ to $\underline{r}=.29$ range are practically insignificant because of the small portion of variance they account for. Thus, number of clubs can be considered as a related component to social 


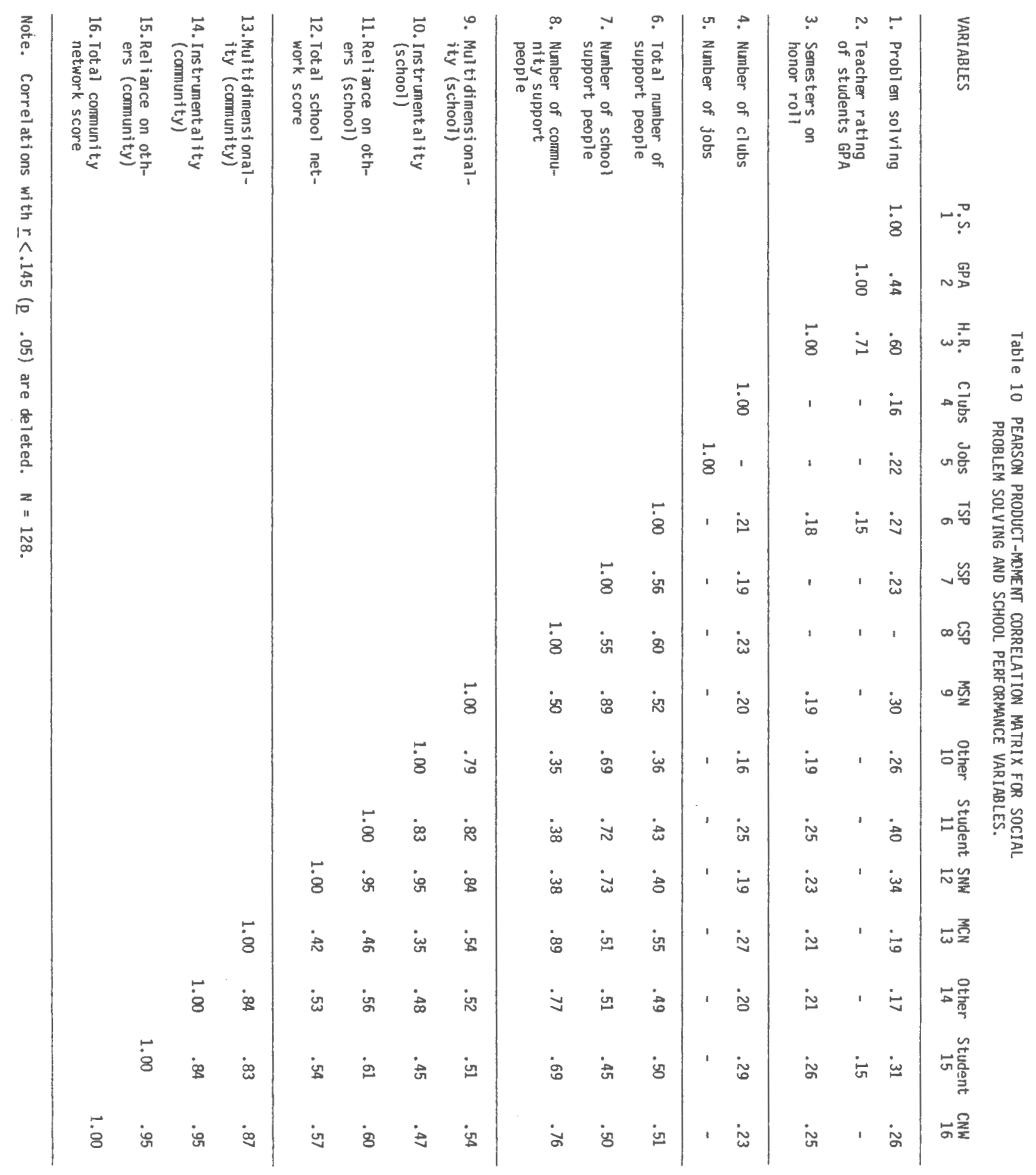


Table 11. PEARSON PRODUCT-MOMENT CORRELATION MATRIX FOR MEANS-END PROBLEM SOLVING MEASURE

\begin{tabular}{|c|c|c|c|c|c|c|c|c|c|c|c|c|}
\hline & VARIABLES & $T$ & 1 & 2 & 3 & 4 & 5 & 6 & 7 & 8 & 9 & 10 \\
\hline T. & $\begin{array}{l}\text { Total Problem } \\
\text { Solving Score }\end{array}$ & 1.00 & .64 & .50 & .59 & .54 & .44 & .43 & .47 & .36 & .45 & .40 \\
\hline 1. & Problem 1 & & 1.00 & .30 & .36 & .35 & .10 & .18 & .21 & .21 & .30 & .09 \\
\hline 2. & Problem 2 & & & 1.00 & .37 & .30 & .15 & .04 & .02 & .04 & .11 & .11 \\
\hline 3. & Problem 3 & & & & 1.00 & .28 & .16 & .11 & .12 & .13 & .25 & .18 \\
\hline 4. & Problem 4 & & & & & 1.00 & .13 & .07 & .08 & .16 & .07 & .18 \\
\hline 5. & Problem 5 & & & · & & & 1.00 & .01 & .13 & -.05 & .24 & .24 \\
\hline 6. & Problem 6 & & & & & & & 1.00 & .17 & .09 & .06 & -.03 \\
\hline 7. & Problem 7 & & & & & & & & 1.00 & .03 & .11 & .13 \\
\hline 8. & Problem 8 & & & & & & & & & 1.00 & .16 & .17 \\
\hline 9. & Problem 9 & & & & & & & & & & 1.00 & .20 \\
\hline 10 & Problem 10 & & & & & & & & & & & 1.00 \\
\hline
\end{tabular}

Note. $N=128$. 
networks. By contrast, number of jobs, an index of community involvement, (or an economic reality) was not significantly related to any of the school or community performance variables.

The school and community network indices have significantly high intercorrelations with each other $\underline{r}=.42$ to $\underline{r}=.57$. Within the school network, the measures of multidimensionality, instrumentality, reliance on others and total network score correl ate highly with each other $\underline{r}=.79$ to $\underline{r}=.95$ (see Table 10). The same trend exists in the community network scale, multidimensionality, instrumentality, reliance on others, and total network score intercorrel ate highly $\underline{r}=.83$ to $\underline{r}=$ .95. These data suggest that the school network indices are 1 argely measuring the same thing. A similar statement may be offered for the comunity network indices. The intercorrel ations between the school and community networks are significantiy high as well, $\underline{r}=.35$ to $\underline{r}=$ .61 (see Table 10). Although there appears to be a. strong overlap in inf ormation provided by both the school and community networks, they are also measuring a distinct amount of separate information. That is, it cannot be assumed that if a particular student had a strong network in one area that the other area would be equally well developed.

\section{Problem solving and school performance. A stepwise multiple} regression analysis was used to examine the rel ationships between problem solving skills and school performance and as a further test of the second hypothesis, that higher problem solvers will perform more effectively in school. The total MEPS score, an index of problem solving, was used as the dependent variable. The predictor variable of academic performance included grade point average and numbers of semesters on the honor roll. To address the issue of mulitcollinearity 
between predictors (intercorrelations between .80 and .99 ) the two academic performance variables were grouped together by adding the grade point average $(1=F, 2=D-, 3=D \ldots 13=A+)$ to the number of semesters on the honor roll (0 to 4$)$. This total score was called academic performance and was entered into the regression equation as one variable. In order to effectively combine these two variables the rankings of academic performance had to be reversed (from the way it was reported on the questionnaire) so that a larger number indicated a better g.p.a.

The predictor variables of school social performance included the school network indices, and the number of school clubs. Again, to address the issue of multicolinearity between predictor variables certain social network variables were grouped together into one school social network variable. The school network variable was computed by summing the number of school support people, the multidimensionality score and the total school network score. Number of school clubs did not correl ate highly enough with social networks variables to cause multicolinearity, therefore, it was entered as a separate variable.

A stepwise multiple regression was computed with the aggregate social performance predictor entered into the regression equation first, followed by the aggregate academic performance predictor, and then number of school clubs. The regression equation for problem solving predicted by school performance is written as follows:

Problem solving $=.12$ (social performance) +.60

(academic performance) +.06 (school clubs) +4.70 (constant)

The average contribution of each predictor was calculated by 
entering variables into the regression equation in all possible orders (See Table 12).

Table 12. Relative contributions of each predictor in the problem solving and school performance regression equation

$\underline{\text { Variable }}$

Order

$x_{1}$

$x_{2}$

$x_{3}$

$\begin{array}{llrl}x_{1} x_{2} x_{3} & 94.8 \% & 4.2 \% & 1.0 \% \\ x_{1} x_{3} x_{2} & 94.2 \% & 3.0 \% & 2.2 \% \\ x_{2} x_{1} x_{3} & 83.6 \% & 15.5 \% & 0.9 \% \\ x_{2} x_{3} x_{1} & 82.0 \% & 15.5 \% & 2.5 \% \\ x_{3} x_{1} x_{2} & 90.5 \% & 3.0 \% & 6.5 \% \\ x_{3} x_{2} x_{1} & 82.2 \% & 11.3 \% & 6.5 \% \\ \text { Mean } \% & 88.0 \% & 8.7 \% & 3.3 \%\end{array}$

Note: $X_{1}=$ Total academic performance; $X_{2}=$ Social performance; $x_{3}^{1}=$ School clubs

The regression equation accounted for $44 \%$ of the total variance $(\underline{R}=.66)$. Acadefific performance was found to be the strongest single predictor of social problem solving, contributing an average of $88.0 \%$ of the predicted variance. Sociar performance contributed an average of $8.7 \%$ of the predicted variance. School clubs was not an effective predictor of social problem solving skills. The second hypothesis is strongly supported by these data.

Problem solving and community performance. A stepwise multiple regression analysis was used to examine the relationship between problem solving skills and community performance. The total MEPS score was used as the dependent variable. Community performance included the community social network indices and number of jobs. To address the 
issue of multicolinearity between predictor variables certain cormunity network scores were grouped together to form one network variable. A procedure similar to the school network aggregate variable was followed. The community network variable was computed by summing the number of community network people, the multidimensionality score, and the total community network score. Number of jobs was entered as a separate predictor variable.

A stepwise multiple regression was computed with the aggregate community network variable entered into the regression equation first, followed by number of jobs. The community performance regression equation can be written as follows:

Problem solving $=.16$ (community network) +.19

(number of jobs) +9.79 (constant)

The average contribution of each predictor was calculated by entering the variables into the regression equation in all possible orders (See Table 13).

Table 13. Relative contributions of each predictor in the problem solving and community performance regression equation

$\underline{\text { Variable }}$

Order $\quad x_{1} \quad x_{2}$

\begin{tabular}{lll}
$\mathrm{X}_{1} \mathrm{X}_{2}$ & $40.7 \%$ & $59.3 \%$ \\
$\mathrm{X}_{2} \mathrm{X}_{1}$ & $38.8 \%$ & $61.2 \%$ \\
Mean $\%$ & $39.8 \%$ & $60.2 \%$ \\
\hline
\end{tabular}

Note: $X_{1}=$ Community network; $X_{2}=$ Number of jobs. 
The regression equation accounted for $6.0 \%$ of the total variance $\underline{(R}=.244)$. Number of jobs and community performance accounted for an average of $60.2 \%$ and $39.8 \%$ of the predicted variance, respectively. Both predictors seemed to be providing relatively independent sources of information to the overall prediction of social problem solving skills.

Social problem solving can be predicted by community performance variables of social network and number of jobs. Social problem solving can also be predicted by academic and social performance variables; g.p.a., honor roll, number of clubs and social network. The relationship between school performance and social problem solving is much stronger than the relationship between community performance and problem solving.

\section{Surmary}

The results of the present study offer support for both the first and second hypotheses. Specifically, limited demographic differences were found with school performance variables and problem solving. Grade 1 evel differences were found in academic performance with sophomores exhibiting higher performance than other grade levels. A sex by grade level interaction was found with sophomore males and females functioning higher than other groups at differing grade levels. There were also limited demographic differences in social performance, both in school and in the community. Differential performance by SES. was found across the school social network properties. Usually, upper SES. students performed higher than middle and lower SES. students. However, upper SES. students were not consistently higher than both 1 ower and middle SES. groups, suggesting 
that the differentiation between SES. groups on the school network variables is not stable. Grade level differences were noted on one dimension of the school network (reliance on others) with sophomores, juniors and seniors functioning higher than freshmen. Similarly, grade level differences were found in job participation; seniors had more jobs and more past, year-round jobs than their freshmen, sophomore, and junior counterparts. Grade level differences were also found in social problem solving; freshmen achieved significantly lower problem solving scores than their upper grade level counterparts. Thus, significant support for the first hypothesis was obtained. No differences by sex were found across school and community performance indices. Same SES. and grade level differences were found in selected performance variables .

The second hypothesis was strongly supported by the results of the present study. Problem solving differences were noted in grade point rating, number of semesters on the honor roll, past jobs held, school social network (reliance on others), community social network (reliance on others), and number of reciprocal support rel ationships (both in school and comunity). Consistently, high problem solvers performed more effectively than middle and low problem solvers. Specifically high problem solvers had significantly stronger academic grade ratings and were more able to rely on others for support than lower problem solvers. Further, the support relationships tended to be reciprocal in nature; equal amounts of recreational, emotional, and physical support were given and received.

Multiple regression analyses indicated that problem solving can be predicted effectively by academic and social performance in high school 
and by community performance indicators. The strongest single predictor of problem solving is academic performance $(\underline{r}=.64)$. However, social network variables both in school and in the community were strong predictors of problem solving ability. Also, number of jobs held accounted for a significant portion of the variance. Club participation (school and community) was not a significant predictor of problem solving ability. These results also offer strong support for the second hypothesis. 


\section{DISCUSSION}

The present research has explored the relationship between social problem solving skills and adolescents' academic and social performance. In general, the results confimed the hypothesis that social problem solving skills are significantly related to high school academic and social performance. Also, the results indicate that problem solving skills are significantly related to comunity performance. Performance in school and community was found to be positively related. These findings are consistent with past studies that link social problem solving skills to notions of school adjustment and personat competence.

The data also indicated that certain demographic differences existed in social problem solving skills and school performance, contrary to the first hypothesis. While no sex differences were found socioeconomic and grade level differences were obtained.

The discussion section will be organized in the following manner. First, the results of this study will be compared with past theory and research. In particular, the following themes will be discussed: the relationship between social problem solving skills and broader notions of school and environmental performance; (2) the relationship between social problem solving skills and performance in different environments; the "transfer" of social problem solving as a construct; and (3) the development of social problem solving skills in adolescence as a function of experience and cognitive factors. Next, the implications for further research will be discussed with an emphasis on longitudinal methodology and cross-situational experiments to verify 
same of the theoretical notions just postulated. Finally, the present findings will be discussed in terms of implications for psychological service delivery in the schools, especially within a primary preventive framework.

\section{Demographic Differences}

The data indicate that demographic differences existed in the development of school social support networks. Specifically, upper SES. students had developed more extensive social support relationships in school than middle and lower SES. groups. However, the differences between upper, middle, and lower SES. groups were not consistent across all school social network variables. That is, upper SES. students performed more effectively than middle SES. students, but not more effectively than lower SES. students on variables measuring network size in the school and community. On variables measuring support given and received, upper SES. students were usually higher than both middle and lower SES. students. The more effective performance of upper SES. students in developing social support networks in school was not found al ong most of the community social network dimensions. Even though both school and community networks for the students consisted mostly of peers, upper SES. students did not develop more extensive support systems in the community than their middle and lower SES. counterparts. Actually, most students sampled had an effective school and cormunity support network. The. SES. differences found in the present study have not been clearly. identified in past social network research (Mitchel1 \& Trickett, 1981). 
Social Problem Solving and Environmental Performance

The major finding in this study is that social problem solving skills are significantly related to broader notions of academic and social performance in school. The link between social problem solving skills and limited notions of school performance has been established (e.g., Spivack \& Shure, 1974; Spivack, Platt, \& Shure, 1976; Hopper \& Kirschenbaum, Note 1 ). This study provides additional support to Spivack and Shure's model of the interpersonal cognitive problem solving ability of means-ends thinking as a mediator of environmental performance. Specifically, no sex or SES. differences in social problem solving skills were found, consistent with past findings by Spivack, Platt, \& Shure (1976). More importantly, the findings that social problem solving skills in adolescence relate strongly to school and camunity performance suggests that problem solving is a critical skill that enables the individual to negotiate everyday problems and structure support systems across settings. Similarly, Platt and Spivack (1975) state: "...the investigations on real-life problem solving thinking clearly indicate an area of thought process that bears a direct relationship to human adjustment and of which means-ends thinking is an important part". (p. 11)

Platt and Spivack (1975) also state that these cognitive-behavioral processes involve a sensitivity to the presence of human problems, the ability to generate alternative courses of action, the ability to conceptualize the means to solve the problem, and the awareness of the consequences of one's actions. These authors assert that human problemsolving skills have relevance to envirormental perfomance across a wide age span, a broad range of human adaptive ability, and across 
disparate socioeconomic groups (Platt \& Spivack, 1975). The findings in the present study strongly reinforce this model, especially with regard to problem solving skills and school performance and problem solving as a skill that is transferable across situations and envi roments .

A strong association between academic performance and social problem solving skills was found. Although previous studies (Hopper \& Kirschenbaum, Note 1; Spivack \& Shure, 1974; Shure \& Spivack, 1978) have found only minor associations between IQ and means-ends thinking the strength of the association between problem solving ability and academic performance in the present study suggests that both may share a similar set of cognitive-behavioral skills.

Social problem solving skills were found to be associated with social performance in school and in the community. In particular, high problem solvers formed more reciprocal support relationships, held more jobs in the past, and relied more on support personnel in school and in the cormunity than their middle and lower problem solving counterparts. This finding suggests that a problem solving component is associated with school and community performance. It seems that this skill is transferable from one situation to another (e.g., classroom performance, forming support relationships) and from one enviroment to another (e.g., performance in school and performance in the community). High problem solvers in this study functioned more effectively in the $\mathrm{classrom}$ and in deriving support from peers than their lower problem solving counterparts. Similarly, high problem solvers had more past jobs and derived more support from peers in the community than lower problem solvers. The notion that social problem solving as a 
cognitive-behavioral cluster of skills is applicable across many situations is similar to other cognitive-personality dimensions identified by Mischel (1979).

The relationship of social problem solving skills to both school and community performance is similar to the "benign" cycle of campetence stressed by Smith (1968). Smith contended that individuals develop patterns of competence that generate further competent behavior. Social problem solving skills are a strong indicator of a "benign" cycle of competence according to Smith. The present findings indicate that high problem solvers have more past jobs, better academic performance and greater reliance on others in school and community settings than lower problem solvers and suggest that indeed, problem solving is positively related to "benign" cycles of competence. The present findings also support the theory of Hunt (1968) who suggests that social problem solving skills help individuals cope with the everyday problems and vicissitudes they encounter in different envirorments.

The present findings that relate problem solving to community performance are also consistent with social network research. Mitchell (Note 11) has found a significant relationship between means-end thinking and community social network development. Specifically, Mitchell (Note 11) states:

...interpersonal problem-solving style was positively and significantly rel ated to the number of intimates cited by the respondent. While most of the social network literature views the individual as a passive agent within the web of social ties, this finding suggests that the individual may play an active role in structuring the size of his/her network. Clients may have to exercise a variety of interpersonal skills in order to take advantage of the environment provides. 
More generally, this finding suggests the need to look more broadly at the range of coping skills that individuals. use to shape their networks. (pp. 15-16).

The differential performance in school and community areas for various problem solving abilities offers empirical support for the theory of Jahoda (1953) and others who suggest that the social problem solving process is an active coping skill that enables the individual to engage the environment in his/her quest for mastery and self improvement. Further, the present study suggests that social problem solving skills transfer from one setting to another.

The strong association between academic performance and social problem solving skills found in the present study suggests that a significant behavioral-cognitive factor is influencing both of these dimensions. Since other theorists (e.g., Spivack \& Shure, 1974; Hopper \& Kirschenbaum, Note 1; Platt, Spivack, \& Bloom, 1971) have found low positive correlations with measures of general intelligence and social problem solving ability, it seems that general intelligence alone cannot account for the strong positive relationship between academic performance and problem solving skills. This assumption cannot be verified by empirical methods in the present study because IQ data was not available. Intelligence data on the present sample could possibly have provided more of an explanation for the academic performance and problem solving skill relationship. Future studies should attempt to include intelligence as a co-variate.

Development of Social Problem Solving in Adolescence

The results of this study suggest that there are some demographic differences in social problem solving skills and school performance. 
Specifically, grade level differences were found in academic performance, social problem solving skills, and social performance. In academic performance sophamores showed higher functioning than other grade levels. Although this finding is not supported by past studies, it is consistent with other data in the present study. For example, freshmen were significantly lower than sophomores in social problem solving abilities and in the extent to which their social networks were developed. Further, sophomores and upper grade level members tended to rely more on the support personnel in their network for emotional, physical, and recreational assistance than freshmen. Thus, in academic performance, social problem solving skills and social performance in school, differential performance was noted between freshmen and upper grade level members. One explanation for this difference is that upper grade level members are more familiar with the school environment and thus perform more effectively.

Another explanation is also tenable. The possibility that a shift in adaptation to school occurs as a function of the development of interpersonal-cognitive problem solving skills merits further exploration. The work of Piaget as discussed by Flavell (1963) suggests a shift in cognitive devel opment from concrete to formal operational thought occurs between the ages of 11 to 15 . The onset of this new cognitive stage allows the individual to become more precise and extended in his/her construction of reality and aware of previous gaps in understanding. The individual is able to bridge those gaps and create new concepts by formulating hypotheses. Hypotheses can be formulated and tested without actually manipulating concrete objects (Phillips, 1975; Piaget, 1952). Fram this, it could be concluded that 
the ability to efficiently form hypotheses about one's own behavior, what Flavell (1963) calls metacognition, and the behavior of others is greatly enhanced by the onset of formal operational thought. This cognitive development begins before high school; however, the behavioral component of social problem solving depends largely on experience and develops in concert with cognitive abilities. Spivack \& Shure (1974) postulate that social problem solving abilities begin to develop from experience and social modeling at about age four and are well developed by age ten as experience interfaces with more advanced cognitive development. The present study suggests that perhaps another key developmental period for social problem solving exists during the period from the age eleven to fifteen. During this period the individual undergoes a rather dramatic change in the cognitive domain and is able to process conceptual information with greater efficiency. Similarly, the individual is faced with social changes that result from physical development (e.g., puberty) and the increased peer group status. Also, the enviromental shift from junior high to high school takes $\mathrm{pl}$ ace and requires the individual to deal with many complex social situations. The conjunction of cognitive and experiential changes allows the individual to devel op more efficient social problem solving skills for use in settings such as high school. A closer examination of the developmental changes in social problem solving skills during the onset of adolescence would require a longitudinal analysis, tracing one group of individuals through the changes in age and environment.

The ability to generalize the present findings to public high school populations must be tempered somewhat because of the characteristics of the present sample. The school used in the present 
study offers many activities for students, has a large faculty, low student-teacher $\mathrm{cl}$ ass ratios, an extensive curriculum, and many support personnel that are available for counseling, and extra services. Teachers are required to carry a caseload of students in informal counseling and all students are required to participate in an affective education program as a regular class for their first two years in high school. Thus, this group of students has mandated instruction and counseling in dealing with life-oriented, interpersonal, and schoolrel ated problems. These factors must be considered when attempting to generalize the exact pattern of the present results to other high schools with differing enviromental characteristics.

The correl ational nature of the present study and the use of self report indices are also factors that need to be considered in the interpretation of these results. Although the accuracy of self report data in the present study was verified by other indices, additional measures (especially, unobtrusive observations) would be helpful in future research.

In summary, the general trends of the data can be summarized as follows: (1) Social problem solving skills are strongly related to high school and community performance indices; (2) There is a strong rel ationship between social perfomance across enviroments (school and community); (3) The relationship between social problem solving skills and enviromental performance is extended to a normal, well-adjusted adolescent population; (4) There are limited demographic patterns in social problem solving skills, and (5) Social problem solving skills are transferable across school and community environments. 


\section{Implications for Future Research}

The relationship between social problem solving skills and high school performance has initially been explored. Future research in the area should attempt to determine more clearly, the causal relationship between problem solving skills and academic performance, establishment of social networks, (especialiy the reliance on others for support), and job participation. Of particular interest is the difference in problem solving abilities, social network characteristics, and academic performance between freshmen and sophomores. The role of problem solving skills in this adjustment process merits further examination. Similarly, the high school's role in facilitating social problem solving skills and school adjustment should be examined from a longitudinal perspective. That is, students could be followed from 8 th grade through high school to note changes in the acquisition of social problem solving skilis and social support system development more carefuliy. In particular, the manner in which students acquire knowledge of the school's resources would be an important consideration. A longitudinal analysis would be able to distinguish how upper grade level members acquire more effective problem solving skills than freshmen.

Problem solving skills and their relationship to involvement in school activities merits closer examination. In the present study, club and activity participation was narrowly measured by frequency count. The actual activity, duration of involvement, type of involvement, etc. should be examined through correl ational research to determine if social problem solving skills mediate between these factors. Intuitively, one might assume that it does, because of the 
present results in other areas of school performance. One might assume that experience in high school and consequent exposure to the resources (e.g., guidance counseling, peer networks, administration) of the school environment could affect the quality and type of solutions to school-rel ated problems.

\section{Implications for Service Delivery}

The present study has further explicated the role of social problem solving skills in enviromental performance. The notions of active coping and enviromental adjustment as discussed in past theory and research were further substantiated by the present results. While the results of this study cannot directly suggest intervention strategies for imediate use in high schools, same general observations regarding informal preventive interventions can be made.

Social problen solving as an adaptive coping process should be recognized as an important component of psychosocial competence by parents, educators, and professionals providing support services to schools. School psychologists, guidance counselors and special educators might recognize deficits in social problem solving skills in their daily encounters with students. In particular, students who display inconsistent social problem solving skills in response to handling interpersonal conflicts or school-related problems could be taught more effective problem solving skills in the regular classroom format. This could be accomplished through modeling and discussions. Teachers of social science courses might include a problem solving component in their approach to their course.

Social problem solving could also be inctuded in guidance 
counseling and psychological counseling in high school settings. This could be formally accomplished through role-modeling and training in groups or in one-to-one counseling situations where the counsel or would review the dilemmas facing the student or create novel problems. The aim would be to facilitate the development of consequential thinking, means-ends conceptualization, and generation of al ternative solutions. Informally, counselors could encourage students to approach problems in a systematic manner fostering an active role rather than a passive one.

Large scale intervention of a primary preventive format would ideally occur in the first years of high school using a formal groupguidance approach. Students and a trained counsel or would follow a prescribed training course including other dimensions besides social problem solving. Such an approach (e.g., Spivack \& Shure's model) should await further research on problem solving skills training with younger children and further delineation of the development of these skills in adolescents before implementation is possible.

\section{Surmary}

Social problem solving skills are significantly, positively related to school and community performance in the present study. High problem solvers showed more effective academic performance, relied more on their peers for support in school and in the community, had more reciprocal support relationships, and held more jobs in the past than their lower problem solving peers. Thus, social problem solving skills were linked to effective performance in differing environments, suggesting that as a set of skills, it is transferable across enviroments. This finding awaits verification in future research. 
Social problem solving skills and social performance in school were found to differ for freshmen and sophomores. The notion of a developmental period in social problem solving paralleling more advanced cognitive development was posited. School experience could be a significant factor in the development of these skills. Again, this finding awaits verification in future research.

Suggestions were made for including problem solving in regular education curricula and in guidance and psychological counseling. Larger scale preventative programs should be carefully scrutinized before they are implemented on any level. Future research is needed to further delineate the acquisition of social problem solving skills in adolescence and their relationship to high school performance. 
Reference Notes

1. Hopper, R.B., \& Kirschenbaum, D.S. Social problem-solving skills and social competence in preadolescent children. Paper presented at the American Psychological Association, Neri York C ity, September, 1979.

2. Hurley, D.J., Nover, M.L., Plurmer, B.A., \& Solomon, R.S.

Psychological well-being of youth: Confronting ind ividual-schoolcommunity relations. Sympos ium presented at the Fortieth Annual Meeting of the Canadian Psychological Association, Quebec City, Canada, June, 1979.

3. Hurley, D.J. Jr. Human needs assessment. Unpubl ished manuscript. University of Rhode Is Tand, 1978.

4. Larcen, S., Spivack, G., \& Shure, M. Problem-solving thinking and adjustment among dependent-neglected preadolescents. Paper

presented at Eastern Psychological Association, Boston, 1972.

5. Platt, J., \& Spivack, G. Real-life problem-solving thinking in neuropsychiatric patients and controls. Paper presented at the meeting of the Eastern Psychological Association, Atlantic City, N.J., Apri1, 1970 .

6. Platt, J. \& Spivack, G. Studies in problem-solving thinking of psychiatric patients: (I) Patient-control differences; (II) Factoral structure of problem-solving thinking. Paper presented at American Psychological Association, Montreal, Canada, September, 1973 a.

7. Platt, J., Altman, N., \& Altman, D. D imensions of real-1 ife problem-solving thinking in adolescent psychiatric patients. Paper presented at Eastern Psychological Association, Hashington, D.C., 1973 b.

8. Platt, J., \& Spivack, G. Performance in important areas of 1 ife as a source of positive self regard. Paper presented at American Psychological Association, Montreal, Canada, September, 1973 d.

9. Plumer, B.A. The development of social problem-solving skills in children as a critical component of psychological competence. UnpubT ished manuscript. Univers ity of Rhode Island, 1980.

10. Mitchel1, R. Social support, personal networks, and network orientation. Unpublished doctoral dissertation. University of Maryland, T980. 
11. Mitche11, R. Problem-solving, family cl imate, and the social networks of psychiatric clients. Paper presented at the 38th annual meeting of the American Psycholog ical Association; Montreal, Quebec, Canada, September, 1980.

12. Hirsch, B. Natural support systerns and coping with major life changes. Paper presented at the annual meeting of the Western Psychological Association, San Francisco, Apri1, 1978.

13. Platt, J., \& Spivack, G. Factor analytic dimensions of real-life problem-solving thinking. Unpublished manuscript, Department of Menta] Health Sciences, Hahnemann Medical College and Hospital, 1973.

14. Platt, J., \& Spivack, G. Content analys is of real-1 ife problemsolving thinking in psychiatric patients and controls. Paper presented at Eastern Psychological Association, Boston, MA, 1972.

15. Sandler, I.N., \& Barrera, M. Social support as a stress-buffer: A multi-method investigation. Paper presented at the meeting of the American Psy'chological Association, Montreal, Quebec, Canada, September, 1980.

16. Holl ingshead, A.B. Two-factor index of social position. Unpubl ished manuscript. Yale University, 1957.

17. Spivack, G. Personal cormunication by telephone, June, 1980. 


\section{References}

Alexander, J.F., \& Parsons, B.V. Short-term behavioral intervention with del inquent famil ies. Journal of Abnormal Psychology, 1973, 81, 219-225.

Allen, G., Chinsky, J., Larcen, S., Lochman, J.E., \& Sel inger, H. Community psychology and the schools: A multilevel preventive approach. Hitlsdale, N.J.: Earlbaum, 1976.

Allport, G.W. Becoming. New Haven: Yale University Press, 1955.

Anderson, S., \& Messick, S. Social competency in young children. Developmental Psychology, 1974, 10, 282-293.

Asher, J. Toward a neo-field theory of problem-solving. Journal of General Psychology, 1963, 68, 3-8.

Bandura, A. Social Learning Theory. Englewood Cliffs, N.J.: PrenticeHall, 1977.

Bardon, J. School psychology and school psychologists: An approach to an old problem. American Psychologist, 1968, 23, 187-194.

Barker, R.G. \& Gump, P.V. (Eds.). Big school, small school: High school size and student behavior. Stanford, C.A.: Stanford University Press, 1904.

Barron, F. Personal ity style and perceptual choice. Journal of Personal ity, $1952,20,385$.

B ischof, L.J. Interpreting personal ity theories. New York: HarperRow, 1970.

Butler, L., \& Meichenbaum. D. Assessing interpersonal problem-solving. In P.C. Kendall \& S.D. Hollon (Eds.), Assessment strategies for cognitive-behavioral interventions. New York: Academic Press, T980.

Clausen, J.A. Perspective on childhood social ization. In J.A. Clausen (Ed.), Socialization and society. Boston: Little, Brown, and Company, T968.

Coehlo, G.V., Silber, E., and Hamburg, D.A. Use of the student TAT to assess coping behavior in hospital ized, normal, and exceptionally competent college freshmen. Perceptual and Motor Ski1ls, 1962, 14, 355-365.

Coehlo, G.V., Hamburg, D.A. and Murphy, E.B. Coping strategies in a new Tearning environment. Archives of General Psychiatry, 1963, I, 433-443. 
Coehlo, G.V., Solomon, F., Wolff, C., Steinberg, A., and Hamburg, D.A. Predicting coping behavior in college. The Journal of Nervous and Mental Diseases, 1969, 149, 386-397.

Coleman, J.S. Adolescents and the schools. New York: Basic Books, 1965.

Davis, G. Current status of research and theory in human problem solving. Psychological Bulletin, 1966, 66, 36-54.

Duncan, C.P. Recent research on human problem-solving. Psychological Bullet in, 1959, 56, 397-429.

Duncker, K. On problem solving. Psychology Monographs, 1945, 58, 1-9.

D'Zurilla, T.J., \& Goldried, M.R. Problem-solving and behavior modification. Journal of Abnormal Psychology, 1971, 78, 107-126.

Feldhusen, J., \& Houtz, J. Problem solving and the concrete-abstract dimension. Gifted Child Quarterly, 1975, 19, 122-129.

Flavel1, J.H. The developmental psychology of Jean Piaget. Princeton: D. Van Nostrand Co., Inc., 1963.

Freud, S. The complete psychological works of Sigmund Freud. Standard Edition. London: Hogarth Press, 1952-1974 (24 volumes).

From, E. Man for himself. Rhinehart, 1947.

Haan, N. A proposed model of ego functioning: Coping and defense mechanisms in relationship to 1.Q. Psychological Monographs, 1963, TI, N0. 8 .

Hartmann, H. Ego psychology and the problem of adaptation. In D. Rapaport (Ed.), Organization and pathology of thought. Columbia University Press, 195ॉ.

Hartmann, H. Essays on ego psychology. New York: International Univers ities Press, 1964.

Hoffman, L.W. Changes in family roles, socialization, and sex differences. American Psycholog ist, 1977, 32, 644-657.

Houtz, J., \& Feldhusen, J. The modif ication of fourth graders' problem solving abilities. Journal of Psychology, 1976, 93, 229-237.

Hunt, J.McV. Toward the prevention of incompetence. In J.W. Carter, Jr. (Ed.), Research contributions from psychology to community mental health. New York: Behavioral Publications, T968.

Jahoda, M. The meaning of psychological health. Social Casework, 1953, 34, 349-354. 
Jahoda, M. Current concepts of positive mental health. New York: Bas ic Books, 1958.

Jaquette, D.A. A case study of social-cognitive development in a natural istic setting. In R.L. Selman (Ed.), The growth of interpersonal understanding: Development and cl inical analys is. New York: Academic Press, 1980.

Jensen, A.R. The role of verbal mediation in mental development. Journal of Genetic Psychology, 1971, 118, 39-70.

Johnson, S.M., \& Bolstad, O.D. Methodological issues in natural istic observation: Some problems and solutions for field research. In L.A. Hamerlynck, L. Handy, and E. Mash (Eds.), Behavior change: methodology concepts, and practice. Champaign, IL: Research Press, T973.

Jones, W.H. Exploratory behavior of adolescents in a dyadic, problemsolving situation. In J.G. Kelly (Ed.), Adolescent boys in high school: A psychological study of coping and adaptation. Hillsdale, N.J.: Lavirence ErTbaum, 1979.

Jung, S.M. \& Moore, J.C. The accuracy of self reported high school grades. College and University, 1970, 45, 225-229.

Kelly, G.A. The psychology- of personal constructs, (Vol. 1 \& 2), New York: Norton, 1955.

Kelly, G.A. Man's construction of his alternatives. In G. Lindzey (Ed.), Assessment of human motives, New York: Holt, Rhinehart, Hinston, Inc., 7958.

Kelly, J.G. (Ed.) Adolescent boys in high school: A psychological study of coping and adaptation. Hillsdale, N.J.: Lawrence ErTbaum, T919. (a).

Kelly, J.G. Exploratory behavior, socialization, and the $h$ igh school environment. In J.G. Kelly (Ed.), Adolescent boys in high school: A psychological study of coping and adaptation. Hillsdale, N.J.: Lawrence ErTbaum, 1979. (b).

Kelly, J.G. Toward an ecological conception of preventive interventions. In D. Adel son, \& B.L. Kal is (Eds.), Community psychology and mental health: Perspectives and challenges. Scranton, Pa.: Chandler, 1970 .

Kerl inger, F.N. Foundations of behavioral research. New York: Holt, Rinehart, and linston, 1973.

Levinson, M., \& Neuringer, C. Problem-solving behavior in suicidal adolescents. Journal of Consulting and Clinical Psychology, 1971, 37, $433-436$. 
Lindeman, R., Merenda, P., \& Gold, R. Introduction to bivariate and multivariate analysis. Glenview, IL: Scott Foresman, 1980.

Loevinger, J. The meaning and measurement of ego development. American Psychologist, 1966, 21, 195-206.

Maccoby, E., \& Jackl in, C. The psychology of sex differences. Stanford: Stanford University Press, 1974.

Maslow, A. Def ic iency motivation and growth motivation. In M.R. Jones (Ed.), Nebraska Symposium on Motivation. University of Mebraska Press, T955.

McClelland, D.C. Testing for competence rather than for intell igence. American Psychologists, 1973, 28, 1-14.

McClure, L.F., Chinsky, J.M., \& Larcen, S.W. Enhancing social problemsolving performance in an elementary school setting. Journal of Eduational Psychology, 1978, 70, 504-513.

Merrifield, P.R., Guilford, J.P. Christensen, P.R., \& Frick, J.H. The role of intellectual factors in problem-solving. Psychological Monographs, $1962, \underline{76}$.

Mischel, H. Personal ity and assessment. New York: Wiley, 1968.

Mischel, W. Toward a cognitive social learning reconceptual ization of personal ity. Psychological Review. 1973, 80, 252-283.

Mischel, W. On the interface of cognition and personality. American Psycholog ist, $1979,34,740-754$.

Mitchell, R., Barbarin, 0., \& Hurley, D.J. Jr. Problem Solving, resource util ization and community involvement in a black and a white community. American Journal of Cormunity Psychology, 1981.

Mitchell, R., \& Trickett, E.J. Social network research and psychological adaptation: Impl ications for community mental heal th practice. In Paul Insel (Ed.), Cl imate of mental heal th: Perspectives in prevention, in press.

Monte, C.F. Beneath the mask: An introduction to theories of personal ity. New York: Praeger Publ ishers, 1977.

Murphy, L. The widening world of childhood: Paths toward mastery. New York: Bas ic Books, 1962.

0 jemann, R.H. Incorporating psychological concepts in the school curriculum. Journal of School Psychology, 1967, $\underline{5}, 195-204$. 
Ojemann, R.H., Levitt, E., Lyle, W., \& Whiteside, M.F. The effects of a "causal" teacher training progran and certain curricular changes on grade school children. Journal of Experimental Education, 1955, 24, $95-114$.

Parsons, B.V., \& Alexander, J.F. Short-term family intervention: A therapy outcome study. Journal of Consulting and Clinical Psychology, 1973, 81, 219-225.

Perry, J.D. The rel iabil ity of high school averages computed from students' estimates of their high school grades. School and Soc iety, $1940,52,3-64$.

Phillips, J.L. The origins of intellect: Piaget's theory, 2nd edition. San Francisco: H.H. Freeman and Company, 1975.

Piaget, J. The origins of intelligence in children. New York: International Universities Press, 1952.

Platt, J., Scura, W., \& Hannon, J.R. Problem-solving thinking of youthful incarcerated heroin addicts. Journal of Community Psychology, 1973, 1, 278-281.

Platt, J., \& Spivack, G. Problem-solving thinking of psychiatric patients. Journal of Consulting and Cl inical Psychology, 1972 a, $39,148-151$.

Platt, J., \& Spivack, G. Social competence and effective problemsolving thinking in psychiatric patients. Journal of $\mathrm{Cl}$ inical Psychology, 1972 b, 28, 3-5.

Platt, J., \& Spivack, G. Means of solving real-1 ife problems: 1. Psychiatric patients versus controls, and 2. Cross-cultural comparison of nornal females. Journal of Community Psychology, 1974a, 2 , $45-48$.

Platt, J., \& Spivack, G. Unidinensional ity of the Mean-Ends ProblemSolving (MEPS) procedure. Journal of Cl inical Psychology, 1974 b.

Platt, J., Spivack, G., Altman, N., Altman, D., \& Peizer, S. Adolescent problem-solving thinking. Journal of Consulting and Cl inical Psychology, 1974 c.

Platt, J., \& Spivack, G. Manual for the means-ends problem-solving procedure (MEPS): A measure of interpersonal cognitive problem-solving skill. Philadelphia: Department of Mental Health Sciences, Hahnemann Medical College and Hostpital, 1975.

Platt, J., \& Spivack, G. Measures of interpersonal cognitive problem-solving for adults and adolescents. Philadelphia:

Department of Mental Health Sciences, Hahnemann Medical College and Hosp ital, 1977. 
Posner, M.I. Memory and thought in human intellectual performance. British Journal of Psychology, 1965, 56, 197-215.

Rob in, A.L., Kent, R., O'Leary, D., Foster, S., \& Prinz, R. An approach to teaching parents and adolescents problem-solving commun ication skills: A prel iminary report. Behavior Therapy, 1977, $\underline{8}, 639-643$.

Rogers, C. Significance of the self-regarding attitudes and perceptions, in M.L. Reymart (Ed.), Feel ings and Emotions. New York: McGraw-Hill, 1950.

Sarason, S.B. The culture of the school and the problem of change. Boston: AlTyn and Bacon, T9ाT.

Sheerer, M. Problem-solving. Scient if ic American, 1963, 208, 118-128.

Shure, M.B. Training children to solve interpersonal problems: A preventive mental health program. In R.F. Munoz, L.R. Snowden, \& J. G. Kelly (Eds.), Social and psychological research in community settings. San Francisco: Jossey-Boss, 1979.

Simon, H., \& Newell, A. Human problem-solving: The state of the theory in 1970. American Psycholog ist, 1971, 26, 145-159.

Smith, M.B. Optima of mental health. Psychiatry, 1950, 13, 503.

Smith, M.B. Research strategies toward a conception of positive mental health. American Psychologist, 1959, 14, 673-681.

Smith, M.B. Competence and social ization. In J.A. Clausen (Ed.), Soc ial ization and soc iety. Boston: Little, Brown and Company, T968.

Smith, M.B. Perspectives on selfhood. American Psychologist, 1978, 33, 1053-1063.

Spivack, G., \& Shure, M. The social adjustment of young children. New York: Jossey Bass, 1974.

Spivack, G., P1att, J., \& Shure, M. The problem-solving approach to adjustment: A guide to research and intervention. San Francisco: Jossey-Bass, T976.

Stein, A.H. \& Bailey, M.M. The socialization of achievenent or ientation in females. Psychological Bullet in, 1973, 80, 345-366.

Sternberg, R.J. Stalking the IQ quark. Psychology Today, September, $1979,42-54$.

Tolsdorf, C.C. Social networks, support, and coping: An exploratory study. Family Process, 1976, 15, 407-417. 
Tyler, F.B., \& Gatz, M. Development of individual psychosocial competence in a high school setting. Journals of Consulting and Cl inical Psychology, 1977, 3 , 441-449.

Tyler, F.B. Individual psychosocial competence: A personality configuration. Journal of Educational and Psychological Measurement, $1978,38,309-323$.

Urbain, E.S., \& Kenda11, P.C. Review of social-cognitive problemsolving interventions with children. Psychological Bulletin, 1980, $88,109-143$.

White, R. Motivation reconsidered: The concept of competence. Psychological Review, 1959, 66, 297-333.

White, R.W. Ego and real ity in psychoanalytic theory. Psychological Issues, 1963, 3 , Monograph 11 .

White, R.W. Strategies of adaptation: An attempt at systematic description. In G.V. Coehlo, D.A. Hamburg, \& J.E. Adams (Eds.), Coping and adaptation. New York: Basic Books, Inc., 1974.

Hiner, B.J. Statistical principles in experimental designs, 2nd edition. New York: McGraw-Hi11, 1971.

Zigler, E.: \& Trickett, P. IQ, social competence, and evaluation of early childhood intervention programs. American Psychologist, $1978,33,789-798$. 
APPENDIX A

QUESTIONNAIRE 
No.

WE ARE HERE TODAY TO STUDY YOUR SCHOOL. IN PARTICULAR, WE ARE INTERESTED IN HOW STUDENTS SOLVE PROBLEMS. THIS IS NOT A TEST. THERE ARE NO RIGHT OR WRONG ANSWERS. WE ARE NOT INTERESTED IN ANY ONE STUDENT ALONE, BUT IN THE OPINIONS OF ALL STUDENTS. THEREFORE, WE URGE YOU TO BE AS TRUTHFUL AS POSS IBLE, SINCE YOUR NAME WILL NOT APPEAR ON THE SURVEY.

RESPONSES TO ANY OF THE QUESTIONS ARE VOLUNTARY.

THANK YOU FOR YOUR COOPERATION. 
Age

Grade

Sex:

Male

(circle one)

Occupation

Education:

(Check the

appropriate

line for

your father

and your

mother) less than 10th grade

10th grade

11th grade

High School Graduate

Same college

College Graduate

Advanced Degree

In this procedure we are interested in your imagination. You are to make up some stories. For each story you will be given the beginning of the story and how the story ends. Your job is to make up a story that connects the beginning that is given to you with the ending given you. In other words, you will make up the middle of the story.

Write at least one paragraph for each story.

1. Mr. A. was listening to the people speak at a meeting about how to make things better in his neighborhood. He wanted to say samething important and have a chance to be a leader too. The story ends with him being elected leader and presenting a speech. You begin the story at the meeting where he wanted to have a chance to be a leader. 
2. H. loved his girlfriend very much, but they had many arguments. One day she left him. H. wanted things to be better. The story ends with everything fine between him and his girlfriend. You begin the story with his girlfriend leaving him after an argument.

3. Mr. P. came hame after shopping and found that he had lost his watch. He was very upset about it. The story ends with Mr. P. finding his watch and feeling good about it. You begin the story where Mr. P. found that he had lost his watch.

4. Mr. C. had just moved in that day and didn't know anyone. Mr. C. wanted to have friends in the neighborhood. The story ends with Mr. C. having many good friends and feeling at hame in the neighborhood. You begin the story with $\mathrm{Mr}$. C. in his room immediately after arriving in the neighborhood. 
5. During the Nazi occupation a man's wife and children were viciously tortured and killed by an SS trooper, and the man swore revenge. The story begins one day after the war, when the man enters a restaurant and sees the ex-SS trooper. The story ends with the man killing the SS trooper. You begin when he sees the SS trooper.

6. One day Al saw a beautiful girl he had never seen before while eating in a restaurant. He was immediately attracted to her. The story ends when they get married. You begin when Al first notices the girl in the irestaurant.

7. Bob needed money badly. The story begins one day when he notices a valuable diamond in a shop window. Bob decides to steal it. The story ends when he succeeds in stealing the diamond. You begin when he sees the diamond. 
8. John noticed that his friends seemed to be avoiding him. John wanted to have friends and be liked. The story ends when John's friends like him again. You begin where he first notices his friends avoiding him.

9. One day George was standing around with some other people when one of them said something very nasty to George. George got very mad. George got so mad he decided to get even with the other person. The story ends with George happy because he got even. You begin the story when George decided to get even.

10. Joe is having trouble getting along with the foreman on his job. Joe is very unhappy about this. The story ends with Joe's foreman liking him. You begin the story where Joe isn't getting along with his foreman. 


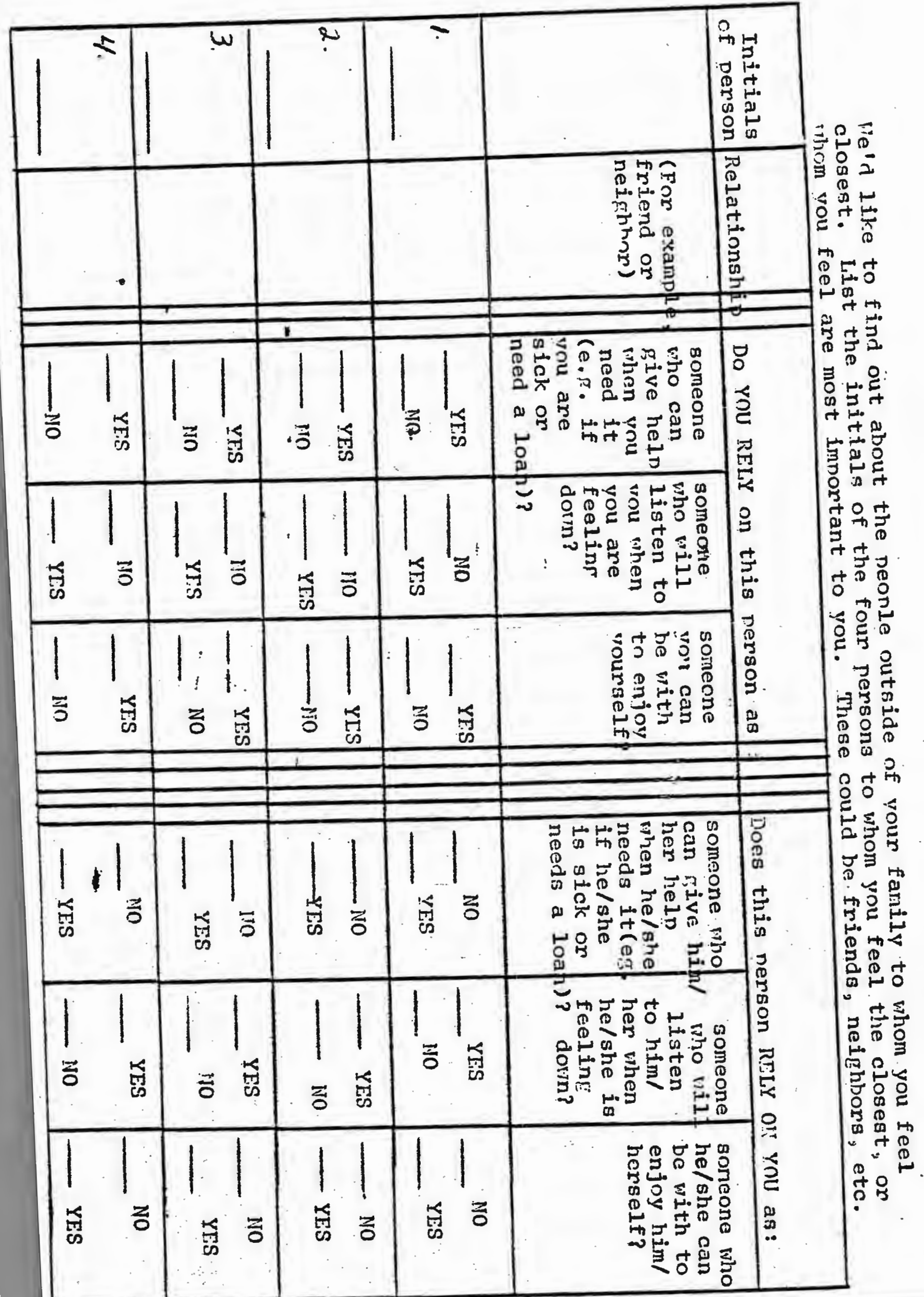




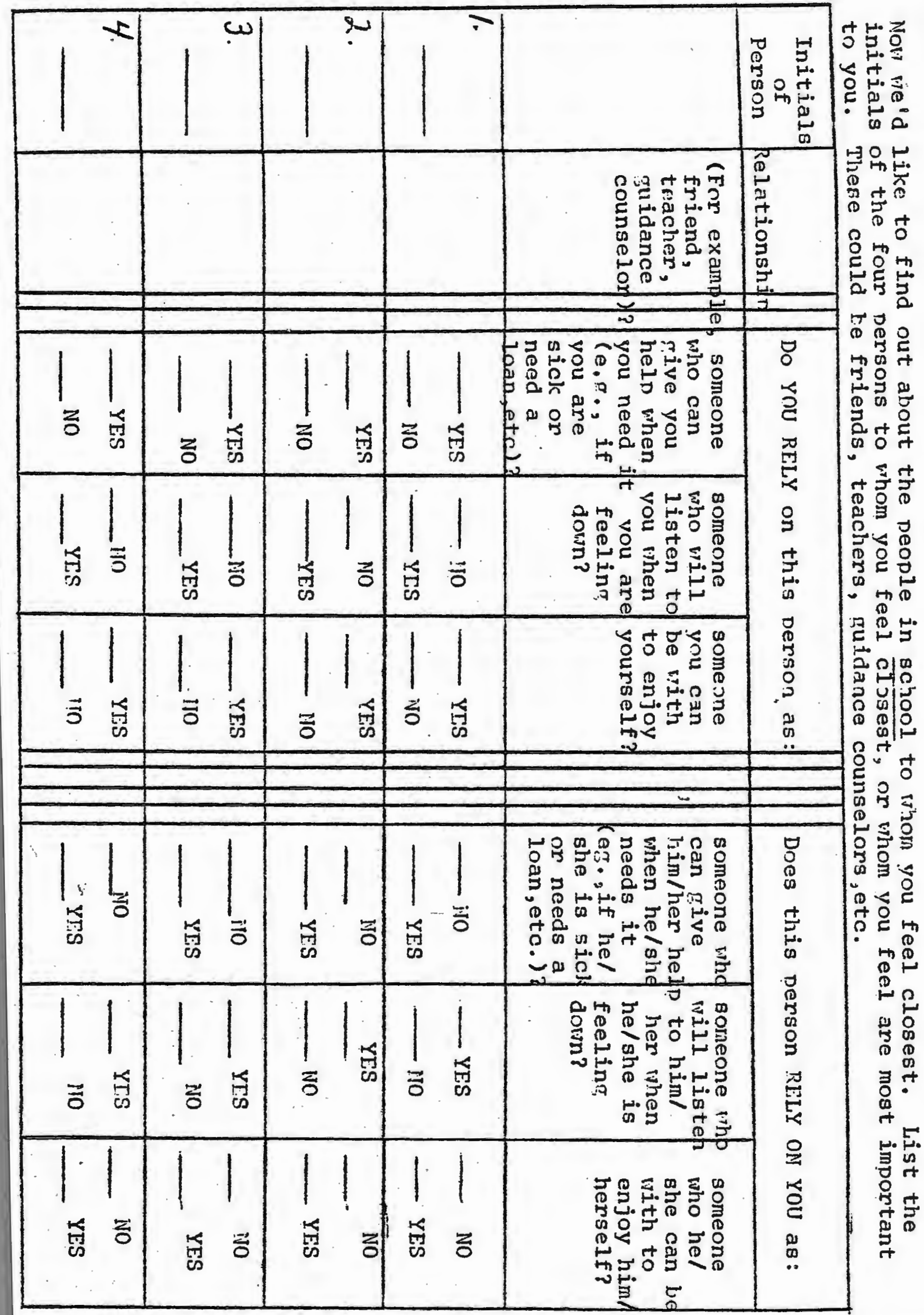


APPENDIX B

Correspondence 


\section{HAHNEMANN MEDICAL COLLEGE \& HOSPITAL OF PHILADELPHIF}

Mr. Barry A. Plummer

Providence Mental Health Center, Inc.

160 Broad Street

Providence, R.I. 02903

Dear Mr. Plummer:

I will do my best to answer your questions although I can only. share my impressions in some cases as a consequence of the experience of many in using the MEPS.

I feel the test-retest reliability is acceptable in considering that data was obtained on aberrant population, in some cases with significant lapse in time between test and retest. I would wish it was some-what higher, and it probably would be if test-retest were done with normal population with a week or two lapsing in between.

In general I am satisfied with the validity of the MEPS: there are now numerous studies indicating it differentiates between and within groups in ways consistent with ICPS theory.

The MEPS. is the best ICPS measure available currently for adolescents. Unfortunately, no careful study of abbreviated forms of MEPS has been done. There is evidance that among adults there is internal consistency among the stories. My own impression is that I would feel safer using four stories rather than three stories. Stories 1, 2, 3, 4, and 7 seem to load higher on the common element being tapped (at least among adult patients). However, one must also consider the appropriateness of the content of the story. Again, among adults eight and nine tend to have lower loadings. I regret, for your sake and mine, that more is not known about which are the best stories for teenagers.

Do I understand you correctly in that you have data on stories 2, 3, and 8? If so, how do they intercorrelate among the teenagers? 
I would appreciate your full reference to Hopper and Kirschenbaum (1979), if you get a chance to drop me a card.

In sumary, let me say that the MEPS seers to be reliable and sensitive enough to pick up significant differences between groups. It relates to a variety of measures of level of adjustment.

sincezely,

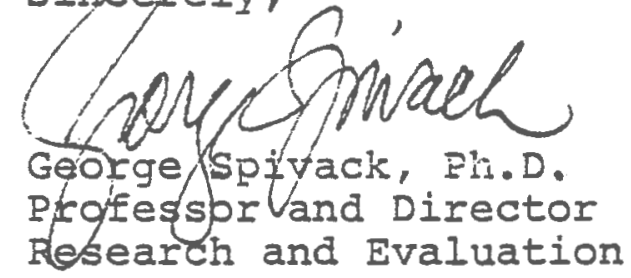

GS : T 


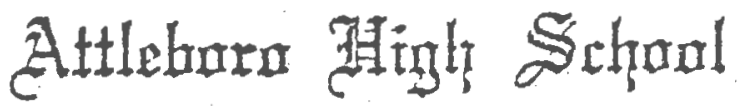

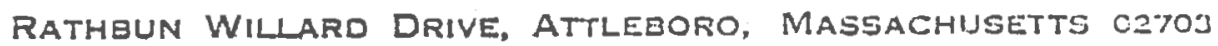

Rubert H. Uray, Principul

Roussclle, llouse uramser

Struminshi, Ilouneuastor

Aluturca, llowar inuster

Lollaud, Allw, of Oce. Ed.

Ilasererty, C. O. A. 1. .

haniel Sage, Ph. D.

ordinator of Research

versity of Rhode Island

igston, Rhode Island 02881

ar Dr. Sage:

I am writing to you regarding a research project currently being run at leboro High School by Barry A. Plummer, a doctoral candidate in psiycholat the University of Rhode Island. Barry has discussed the project with icus administrators and teachers in the Attleboro school system, conseintly the project is approved by the Assistant Superintendent of Schouls and self as sound, applied research that addresses the rights of students.

The questionaires that were distributed are confidential and anonymous. sidering that no risks are involved to the students, I have given consent for students from Social Studies classes and Guidance groups to participate he study.

Sincerely,

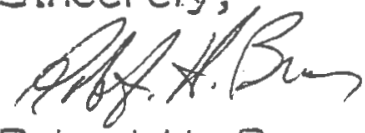

Robert H. Bray

Principal 
APPENDIX C ANALYSIS OF VARIANCE SUMMARY TABLES 
APPENDIX C. ANALYSIS OF VARIANCE SUMMARY TABLES

Variable

Problem Solving

Sex

S.E.S

Grade Level (G.L.)

Sex X S.E.S.

Sex X G.L.

G.L.X S.E.S.

Error

Teacher Rating of

Student G.P.A.

Problem Solving (PS)

Sex

S.E.S

G.L.

PS $x$ Sex

PS $X$ S.E.S

PS X G.L.

Sex X S.E.S.

Sex X G.L.

S.E.S. X G.L.

Error
SS

2.870

19.003

155.645

19.587

3.078

70.150

937.028
DF

1

2

3

2

3

6

110

MS

F

0.337

1.115

9.501

$6.097 * \star *$

51.882

1.150

9.794

0.120

1.026

1.373

11.692

8.518 
Number of Community Clubs

\begin{tabular}{lcccc} 
PS & 0.380 & 2 & 0.190 & 0.468 \\
Sex & 0.210 & 1 & 0.210 & 0.516 \\
G.L. & 0.699 & 3 & 0.233 & 0.574 \\
S.E.S & 0.167 & 2 & 0.084 & 0.206 \\
PS X Sex & 5.044 & 2 & 2.522 & $6.211 * *$ \\
PS X S.E.S & 6.160 & 4 & 1.540 & $3.793^{\star} *$ \\
PS X G.L. & 2.348 & 6 & 0.391 & 0.964 \\
Sex X S.E.S. & 1.330 & 2 & 0.665 & 1.638 \\
Sex X G.L. & 4.096 & 3 & 1.365 & $3.362 *$ \\
S.E.S. X G.L. & 5.556 & 6 & 0.926 & $2.280 *$ \\
Error & 38.982 & 96 & 0.406 & \\
\hline
\end{tabular}

Number of Jobs:-

\begin{tabular}{lrrrl} 
PS & 3.833 & 2 & 1.916 & 2.076 \\
Sex & 0.075 & 1 & 0.075 & 0.081 \\
G.L. & 22.737 & 3 & 7.579 & $8.209 * * *$ \\
S.E.S & 5.214 & 2 & 2.607 & 2.824 \\
PS X Sex & 1.717 & 2 & 0.858 & 0.930 \\
PS X G.L. & 2.227 & 6 & 0.371 & 0.402 \\
PS X S.E.S. & 4.042 & 4 & 1.011 & 1.095 \\
Sex X G.L.. & 1.709 & 3 & 0.570 & 0.617 \\
Sex X S.E.S. & 0.211 & 2 & 0.105 & 0.114 \\
G.L.X S.E.S. & 5.247 & 6 & 0.875 & 0.947 \\
Error & 88.631 & 96 & 0.923 & \\
\hline
\end{tabular}


F

Total Support People

$\begin{array}{lrrrr}\text { PS } & 12.392 & 2 & 6.196 & 2.890 \\ \text { Sex } & 0.940 & 1 & 0.940 & 0.439 \\ \text { G.L. } & 15.625 & 3 & 5.208 & 2.429 \\ \text { S.E.S } & 22.060 & 2 & 11.030 & 5.144 * \star \\ \text { PS X Sex } & 0.035 & 2 & 0.175 & 0.082 \\ \text { PS X G.L. } & 20.767 & 6 & 3.461 & 1.614 \\ \text { PS X S.E.S. } & 3.783 & 4 & 0.946 & 0.441 \\ \text { Sex X G.L. } & 1.592 & 3 & 0.531 & 0.248 \\ \text { Sex X S.E.S. } & 1.443 & 2 & 0.721 & 0.336 \\ \text { G.L. X S.E.S. } & 26.609 & 6 & 4.435 & 2.068 \\ \text { Error } & 205.841 & 96 & 2.144 & \end{array}$

School Support People

$\begin{array}{lcccc}\text { PS } & 0.615 & 2 & 0.307 & 0.732 \\ \text { Sex } & 0.008 & 1 & 0.008 & 0.018 \\ \text { G.L. } & 0.169 & 3 & 0.056 & 0.134 \\ \text { S.E.S } & 3.500 & 2 & 1.750 & 4.166 \\ \text { PS X Sex } & 0.174 & 2 & 0.087 & 0.207 \\ \text { PS X G.L. } & 4.401 & 6 & 0.734 & 1.746 \\ \text { PS X S.E.S. } & 2.822 & 4 & 0.706 & 1.680 \\ \text { Sex X G.L. } & 1.056 & 3 & 0.352 & 0.838 \\ \text { Sex X S.E.S. } & 1.057 & 2 & 0.529 & 1.258 \\ \text { G.L. X S.E.S. } & 2.829 & 6 & 0.471 & 1.122 \\ \text { Error } & 40.328 & 96 & 0.420 & \end{array}$


$\frac{\text { Variable }}{\text { Community Support People }}$

\begin{tabular}{lcccc} 
PS & 0.170 & 2 & 0.085 & 0.138 \\
Sex & 0.095 & 1 & 0.095 & 0.154 \\
G.L. & 3.555 & 3 & 1.185 & 1.918 \\
S.E.S & 4.174 & 2 & 2.087 & 3.377 * \\
PS X Sex & 1.133 & 2 & 0.567 & 0.917 \\
PS X G.L. & 4.007 & 6 & 0.668 & 1.081 \\
PS X S.E.S. & 1.876 & 4 & 0.469 & 0.759 \\
Sex X G.L. & 1.007 & 3 & 0.336 & 0.543 \\
Sex X S.E.S. & 1.252 & 2 & 0.626 & 1.013 \\
G.L. X S.E.S. & 3.373 & 6 & 0.562 & 0.910 \\
Error & 59.325 & 96 & 0.618 & \\
\hline
\end{tabular}

Multidimens ional ity -

School Network

PS

$\begin{array}{llll}1.454 & 2 & 0.727 & 1.437 \\ 0.024 & 1 & 0.024 & 0.047 \\ 0.417 & 3 & 0.139 & 0.275 \\ 3.949 & 2 & 1.975 & 3.903 * \\ 0.093 & 2 & 0.047 & 0.092 \\ 4.825 & 6 & 0.804 & 1.589 \\ 3.398 & 4 & 0.849 & 1.679 \\ 2.780 & 3 & 0.927 & 1.832 \\ 1.794 & 2 & 0.897 & 1.773 \\ 5.231 & 6 & 0.872 & 1.723 \\ 48.565 & 96 & 0.506 & \end{array}$

Error

DF

MS

F 
Variable

SS

DF

MS

F

Others' (School)

Reliance on Student

$\begin{array}{lrrrr}\text { PS } & 9.606 & 2 & 4.803 & 0.708 \\ \text { Sex } & 0.019 & 1 & 0.019 & 0.003 \\ \text { G.L. } & 42.713 & 3 & 14.238 & 2.098 \\ \text { S.E.S } & 93.885 & 2 & 46.943 & 6.919 \star \star \\ \text { PS X Sex } & 11.466 & 2 & 5.733 & 0.845 \\ \text { PS X G.L. } & 27.361 & 6 & 4.560 & 0.672 \\ \text { PS X S.E.S. } & 54.612 & 4 & 13.653 & 2.012 \\ \text { Sex X G.L. } & 18.768 & 3 & 6.256 & 0.922 \\ \text { Sex X S.E.S. } & 13.375 & 2 & 6.687 & 0.986 \\ \text { G.L. X S.E.S. } & 60.526 & 6 & 10.088 & 1.487 \\ \text { Error . } & 651.367 & 96 & 6.785 & \\ \end{array}$

Students' Rel iance on

Others (School)

\begin{tabular}{lrrrr} 
PS & 34.926 & 2 & 17.463 & $3.021^{\star}$ \\
Sex & 0.291 & 1 & 0.291 & 0.050 \\
G.L. & 53.462 & 3 & 17.821 & $3.083^{\star}$ \\
S.E.S & 44.456 & 2 & 22.228 & $3.845^{\star}$ \\
PS X Sex & 2.011 & 2 & 1.005 & 0.174 \\
PS X G.L. & 26.304 & 6 & 4.384 & 0.758 \\
PS X S.E.S. & 36.119 & 4 & 9.030 & 1.562 \\
Sex X G.L. & 23.823 & 3 & 7.941 & 1.374 \\
Sex X S.E.S. & 13.162 & 2 & 6.581 & 1.138 \\
G.L. X S.E.S. & 39.389 & 6 & 6.565 & 1.136 \\
Error & 554.926 & 96 & 5.780 & \\
\hline
\end{tabular}


Number Semesters

On Honor Roll

$\begin{array}{lrrrr}\text { PS } & 106.294 & 2 & 53.147 & 33.686 \star \star \star \\ \text { S.E.S. } & 8.243 & 2 & 4.122 & 2.612 \\ \text { Sex } & 2.118 & 1 & 2.118 & 1.342 \\ \text { G.L. } & 17.609 & 3 & 5.870 & 3.720 * \\ \text { PS X S.E.S. } & 9.919 & 4 & 2.480 & 1.572 \\ \text { PS X SeX } & 11.072 & 2 & 5.536 & 3.509 * \\ \text { PS X G.L. } & 2.934 & 6 & 0.489 & 0.310 \\ \text { S.E.S. X Sex } & 7.312 & 2 & 3.656 & 2.317 \\ \text { S.E.S. X G.L. } & 13.444 & 6 & 2.241 & 1.420 \\ \text { Sex X G.L. } & 15.835 & 3 & 5.278 & 3.346 \\ \text { Error } & 151.1661 & 96 & 1.578 & \end{array}$

Total School Network

Score

\begin{tabular}{lrrrr} 
PS & 80.924 & 2 & 40.462 & 1.803 \\
Sex & 0.030 & 1 & 0.030 & 0.001 \\
G.L. & 181.157 & 3 & 60.386 & $2.691 *$ \\
S.E.S & 282.863 & 2 & 141.431 & $6.303^{* *}$ \\
PS X Sex & 15.100 & 2 & 7.550 & 0.336 \\
PS X G.L. & 83.232 & 6 & 13.872 & 0.618 \\
PS X S.E.S. & 158.650 & 4 & 39.662 & 1.768 \\
Sex X G.L. & 95.356 & 3 & 31.785 & 1.417 \\
Sex X S.E.S. & 43.753 & 2 & 21.877 & 0.975 \\
G.L. X S.E.S. & 165.959 & 6 & 27.660 & 1.233 \\
Error & 2154.041 & 96 & 22.438 & \\
\hline
\end{tabular}




\begin{tabular}{|c|c|c|c|c|}
\hline Variable & SS & DF & MS & $\mathrm{F}$ \\
\hline \multicolumn{5}{|c|}{$\begin{array}{l}\text { Mul tid imens ional ity - } \\
\text { Commun ity Network }\end{array}$} \\
\hline PS & 1.102 & 2 & 0.551 & 0.782 \\
\hline Sex & 0.252 & 1 & 0.252 & 0.358 \\
\hline G.L. & 2.435 & 3 & 0.812 & 1.152 \\
\hline S.E.S & 2.044 & 2 & 1.022 & 1.451 \\
\hline PS $x$ Sex & 1.570 & 2 & 0.785 & 1.114 \\
\hline PS X G.L. & 5.093 & 6 & 0.849 & 1.205 \\
\hline PS X S.E.S. & 3.007 & 4 & 0.752 & 1.067 \\
\hline Sex X G.L. & 1.937 & 3 & 0.646 & 0.916 \\
\hline Sex X S.E.S. & 1.801 & 2 & 0.900 & 1.278 \\
\hline G.L. X S.E.S. & 5.234 & 6 & 0.872 & 1.238 \\
\hline Error & 89.991 & 96 & 0.705 & \\
\hline
\end{tabular}

Others' Rel iance On

Student (Community)

$\begin{array}{lrrrr}\text { PS } & 10.807 & 2 & 5.403 & 0.746 \\ \text { Sex } & 0.386 & 1 & 0.386 & 0.053 \\ \text { G.L. } & 14.939 & 3 & 4.980 & 0.687 \\ \text { S.E.S } & 37.020 & 2 & 18.510 & 2.555 \\ \text { PS X Sex } & 11.111 & 2 & 5.556 & 0.767 \\ \text { PS X G.L. } & 53.577 & 6 & 8.930 & 1.232 \\ \text { PS X S.E.S. } & 45.361 & 4 & 11.340 & 1.565 \\ \text { Sex X G.L. } & 42.398 & 3 & 14.133 & 1.951 \\ \text { Sex X S.E.S. } & 28.955 & 2 & 14.477 & 1.998 \\ \text { G.L. X S.E.S. } & 58.800 & 6 & 9.800 & 1.353 \\ \text { Error } & 695.547 & 96 & 7.245 & \end{array}$


Students' Rel iance on

others (Comunity)

\begin{tabular}{lrrrr} 
PS & 59.779 & 2 & 29.890 & $3.468 *$ \\
Sex & 2.885 & 1 & 2.885 & 0.335 \\
G.L. & 24.446 & 3 & 8.149 & 0.946 \\
S.E.S & 23.315 & 2 & 11.657 & 1.353 \\
PS X Sex & 7.630 & 2 & 3.815 & 0.443 \\
PS X G.L. & 53.132 & 6 & 8.855 & 1.028 \\
PS X S.E.S. & 34.753 & 4 & 8.688 & 1.008 \\
Sex X G.L. & 20.425 & 3 & 6.808 & 0.790 \\
Sex X S.E.S. & 7.520 & 2 & 3.760 & 0.436 \\
G.L. X S.E.S. & 32.063 & 6 & 5.344 & 0.620 \\
Error & 827.287 & 96 & 8.618 & \\
\hline
\end{tabular}

Total Community

Network Score

\begin{tabular}{lrrrr} 
PS & 134.362 & 2 & 67.181 & 2.317 \\
Sex & 9.641 & 1 & 9.641 & 0.333 \\
G.L. & 91.721 & 3 & 30.574 & 1.054 \\
S.E.S & 124.757 & 2 & 62.379 & 2.151 \\
PS X Sex & 40.224 & 2 & 20.112 & 0.694 \\
PS X G.L. & 172.479 & 6 & 28.746 & 0.991 \\
PS X S.E.S. & 134.441 & 4 & 33.610 & 1.159 \\
Sex X G.L. & 99.891 & 3 & 33.297 & 1.148 \\
Sex X S.E.S. & 43.527 & 2 & 21.764 & 0.751 \\
G.L. X S.E.S. & 159.438 & 6 & 26.573 & 0.916 \\
Error & 2783.530 & 96 & & \\
\hline
\end{tabular}

